\title{
APORTACIONES AL CONOCIMIENTO DE LA EVOLUCIÓN HISTÓRICA DE LA VEGA BAJA DE TOLEDO. ESTUDIO PRELIMINAR DE LA EXCAVACIÓN DE LA PARCELA R-3
}

\section{Contributions to the knowledge of the history of the Vega Baja de Toledo. Preliminary study of the excavation of parcel R-3}

\author{
Yolanda Peña Cervantes, Virginia García-Entero, Javier Gómez Rojo ${ }^{1}$
}

Recibido el 25 de febrero de 2009. Aceptado el 19 de mayo de 2009

Resumen: Se presenta un estudio preliminar de las excavaciones realizadas en la parcela R3 de la Vega Baja de Toledo en 2006. Los trabajos han aportado datos que permiten establecer la evolución histórica de este sector de la ciudad desde el siglo I d. C. hasta el siglo IX. Se ha documentado una actividad extractiva de áridos continuada desde el siglo I d. C. hasta época emiral. Cabe destacar la fase visigoda a la que pertenece un tramo de eje viario que delimita dos espacios domésticos que permiten definir parte del primer urbanismo visigodo de este sector de la ciudad datado en la segunda mitad del siglo VI o inicios del VII d.C. Palabras Clave: Vega Baja, Toledo, Parcela R3, evolución histórica, extracción de áridos, urbanismo visigodo.

Abstract: A preliminary study of the excavations carried out on the R3 parcel of the Vega Baja of Toledo in 2006 is presented. The works have contributed information about the historical evolution of this sector of the city from the $1^{\text {st }}$ century A.D. to the $9^{\text {th }}$ century A.D. A continued extractive activity of barren has been documented from the $1^{\text {st }}$ century A.D. to emiral times. The Visigothic phase of a road axis section that delimits two domestic spaces is emphasized and allows us to define part of the first Visigothic urbanism of this sector of the city dated in the second half of the 6th century A.D. or beginning of the $7^{\text {th }}$ century.

Key words: Vega Baja, Toledo, R3 parcel, historical evolution, extractive activity, visigothic urbanism.

\section{INTRODUCCIÓN}

El espacio conocido como Vega Baja de Toledo se encuentra situado en la margen derecha del río Tajo, en una llanura cuaternaria de depósitos fluviales que se extiende a las afueras -al noroeste- de la actual ciudad, a escasos metros del río y en las proximidades del Campus Universitario de la Fábrica de Armas. Durante los meses de marzo a julio de 2006 se llevó a cabo una excavación arqueológica de carác- ter intensivo ${ }^{2}$, adscrita al proyecto de urbanización de la Vega Baja, en la parcela R3 $\left(2.800 \mathrm{~m}^{2}\right)$ del yacimiento de la Vega Baja (Toledo). Gracias a esta intervención, debido a las características específicas de la parcela que se halla localizada en una zona marginal desde el punto de vista del urbanismo visigodo, se ha podido documentar al completo su secuencia de ocupación (fig. 1). Estos trabajos arqueológicos han permitido la recopilación de información acerca de las caracteristicas y ocupación continuada de este sector de la ciudad

(1) Yolanda Peña Cervantes: yIndcervantes@hotmail.com Virginia Garcia-Entero: Dpto. de Historia Antigua, UNED-Sede Central.vgarciaentero@geo.uned.es. Javier Gómez Rojo: arqueoswing@hotmail.com.

(2) Esta intervención arqueológica, desarrollada bajo la dirección científica de Yolanda Peña Cervantes y Javier Gómez Rojo, fue realizada por el equipo de Arqueología formado por Virginia Garcia-Entero, Cristóbal Burkhalter, Maria Salán, Laura Rodriguez, Laura Lambea y Ramón Navarro. Agradecemos también la colaboración y asesoramiento de Gonzalo Álvarez Toledo, Sergio Vidal Álvarez y Carmen Gallego Rodríguez. 


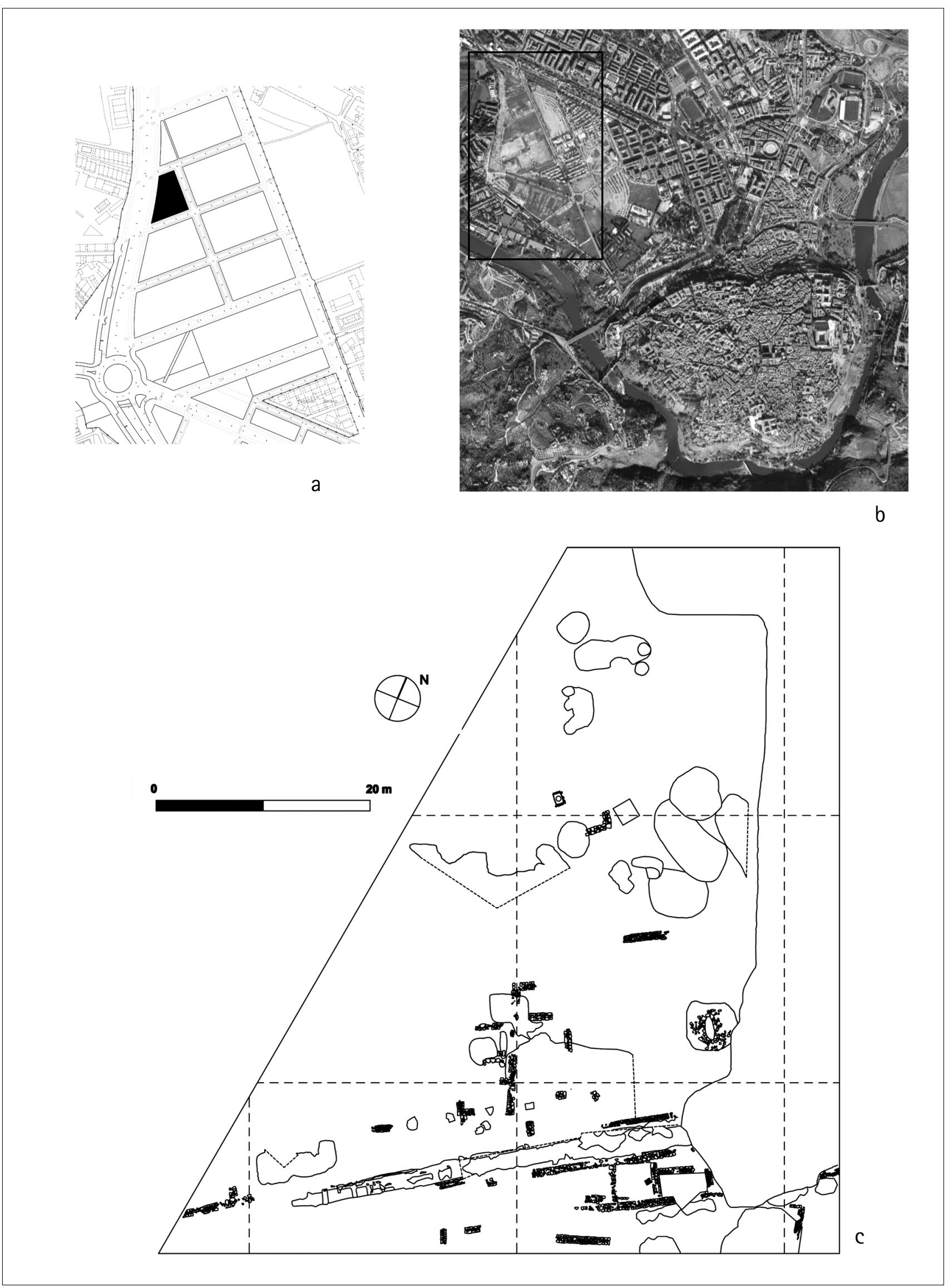

A Figura 1. a. Localización de la parcela R3 en la Vega Baja de Toledo. b. Localización de la Vega Baja de Toledo (foto google earth). c. Planimetría general de la parcela R3. 
de Toledo desde época romana altoimperial -siglo I d. C.hasta época moderna/contemporánea, con especial ocupación romana, tardorromana, visigoda e islámica emiral ${ }^{3}$, siendo la exposición de estos resultados, con carácter preliminar ${ }^{4}$, el objeto de las páginas que siguen.

\section{2. ÉPOCA ROMANA}

Fase 1. Siglo I d.C. (fig. 2)

La evidencia de ocupación más antigua documentada en la parcela R3 de la Vega $\mathrm{Baja}^{5}$ se corresponde con un sondeo de extracción de áridos cuya colmatación se produjo durante la segunda mitad del siglo I d. C.

Se trata de una estructura negativa excavada en el nivel geológico, de planta cuadrada (1,90 x 1,95 m.) y que alcanza una profundidad de $2,8 \mathrm{~m}$. Las dimensiones y morfología de esta fosa de extracción nos permiten determinar con cierta seguridad su función como sondeo de peritación de la potencia y calidad de los limos fluviales sedimentarios de esta zona de la vega toledana. La validez de esta hipótesis, no obstante, deberá ser corroborada con los datos obtenidos en la excavación de otras parcelas del yacimiento de la Vega Baja y la existencia o no de fosas de extracción adscribibles a este período altoimperial.

Desde el punto de vista cronológico, la realización de este sondeo de peritación puede ser datada en un momento inmediatamente anterior a su colmatación, circunstancia que se produce durante la segunda mitad del siglo I d. C., como así evidencian los materiales que la rellenan.
Este sondeo de peritación estaba colmatado por un único relleno sellado, a su vez, con material latericio. Este relleno contenía un conjunto cerámico excepcional ${ }^{6}$, tanto desde un punto de vista cuantitativo como por la calidad y estado de conservación de las piezas. Destacan las cerámicas pintadas tipo "Meseta Sur", producción de la que hemos recuperado 25 piezas prácticamente completas, además de varios cientos de fragmentos ${ }^{7}$. Aparecen así mismo varios fragmentos de TS Sudgálica entre los que destaca un pie con sello del alfarero del taller de La Grauffesenque IVCVNDVS, bien atestiguado en Hispania ${ }^{8}$ y cuya producción data de época claudia/flavia. La TS Hispánica aparece más representada que la sigillata de importación, habiendo documentado varias decenas de fragmentos que se corresponden tanto con piezas decoradas como lisas, adscribibles a cuatro formas concretas relacionadas con el servicio de mesa de plato (forma 18), copa (formas 27 y 35/36) y boles (forma 29). Por otra parte, la terra sigillata hispánica brillante está profusamente representada, siendo mayoritaria la presencia de la forma 9 además de especialmente destacable la de formas inéditas hasta el momento dentro del repertorio de este tipo cerámico ${ }^{9}$. Las paredes finas están también representadas en este relleno a través de varios cubiletes mayoritariamente decorados con la técnica de barbotina (lúnulas y mamelones), burilados y engobados.

El conjunto cerámico más numeroso se corresponde con cerámica común romana de mesa y cocina del que hemos recuperado varios miles de fragmentos. Dentro las producciones de mesa, hemos identificado tres variantes en función de los acabados: imitaciones de terra sigillata ${ }^{10}$, cerámicas engobadas ${ }^{11} \mathrm{y}$

(3) Para simplificar la comprensión de la evolución cronoestratigráfica de la parcela y debido a la dilatada y continuada ocupación de la misma desde el siglo I d. C. a la actualidad, hemos optado por individualizar fases de ocupación en un sentido amplio, englobando los momentos de construcción, uso y amortización en una misma fase siempre y cuando no existan items arqueológicos significativos que nos permitan precisar el hiatus temporal transcurrido entre cada una de estos momentos históricos. En el caso de las fosas de extracción de áridos, contamos además con la naturaleza de los vertidos de colmatación que indican la existencia de un único relleno que, nos inclinamos a pensar, se produce en un lapso de tiempo próximo al momento de abandono de la explotación.

(4) Peña Cervantes, Y. y Gómez Rojo, J. 2006: Memoria Final de la Intervención arqueológica en la Parcela R3, Vega Baja (Toledo), Memoria depositada en la Consejería de Cultura de la JCCM, Toledo (Inédita).

(5) Aunque en posición secundaria, no podemos dejar de mencionar la presencia de tres fragmentos cerámicos asociables al horizonte Cogotas. Se trata de tres fragmentos de cazuela con carena marcada y borde de pared recta. Presentan decoración exterior realizada a base de puntillado que conforma líneas simples paralelas, rombos y zigzag. Las pastas, poco depuradas con desgrasantes muy gruesos, varian del anaranjado al negro en función de la cocción que es muy deficiente y mixta. La superficie interior ha sido alisada y bruñida al igual que la exterior que, además de la decoración de motivos geométricos a base de puntillado, presenta un bruñido.

${ }^{6}$ ) Los materiales de este relleno serán objeto de una próxima publicación monográfica en la que abordaremos detalladamente su estudio.

${ }^{7}$ ) La mayor parte de las piezas pueden adscribirse a tres formas básicas. Los vasos globulares clasificados por J. M. Abascal como Forma 18; tanto de labio sencillo (18a) como labio con acanaladura (18b) con presencia de uno o dos frisos en los ya conocidos tonos vinosos, pardos y negro, que enmarcan motivos espigados, ondulaciones, reticulados, etc. (Abascal 1986: 109-115). También numerosa es la presencia de vasos de forma semiesférica definidos por Abascal como Forma 16, con su característico labio afilado y borde engrosado y cuya decoración se limita a bandas de diferentes grosores de color vinoso, ocre y pardo tanto al interior como al exterior de las piezas (Abascal 1986: 106-107). Por último hemos documentado varias piezas de la Forma 17 de este autor. Su presencia en la Vega Baja podría avalar su fabricación en alfares toledanos, ampliándose, de este modo, el mapa de dispersión hasta ahora conocido.

(8) Cf. Fernández Ochoa et alii 2007.

$\left({ }^{9}\right)$ Caballero y Tovar 1983-84; Fernández Ochoa y Zarzalejos, 2008.

${ }^{(10)}$ Se trata de un conjunto de cerámicas realizadas a torno, de pastas oxidantes, de color anaranjado, bien decantadas, con desgrasantes muy finos y finos y acabados lisos al exterior. Como decimos, las formas imitan, en ocasiones, las sigillatas, siendo el servicio de mesa de cuenco (Drag. 29), taza (Consp. 22) y plato las formas más habituales.

(11) Se trata de cerámica realizada a torno, de cocción oxidante y formas principalmente abiertas (cuencos, ollas, fuentes y lebrillos) aunque también existe alguna forma cerrada y evidencias de algún cántaro (de 2 asas). Las pastas son anaranjadas, decantadas, con desgrasantes medios y finos, y acabados exteriores con engobes de color rojizo uniforme, que en ocasiones pasa al interior de las piezas en forma de lenguas. Los interiores no presentan acabado cuidado, siendo muy evidentes las huellas del torno. 

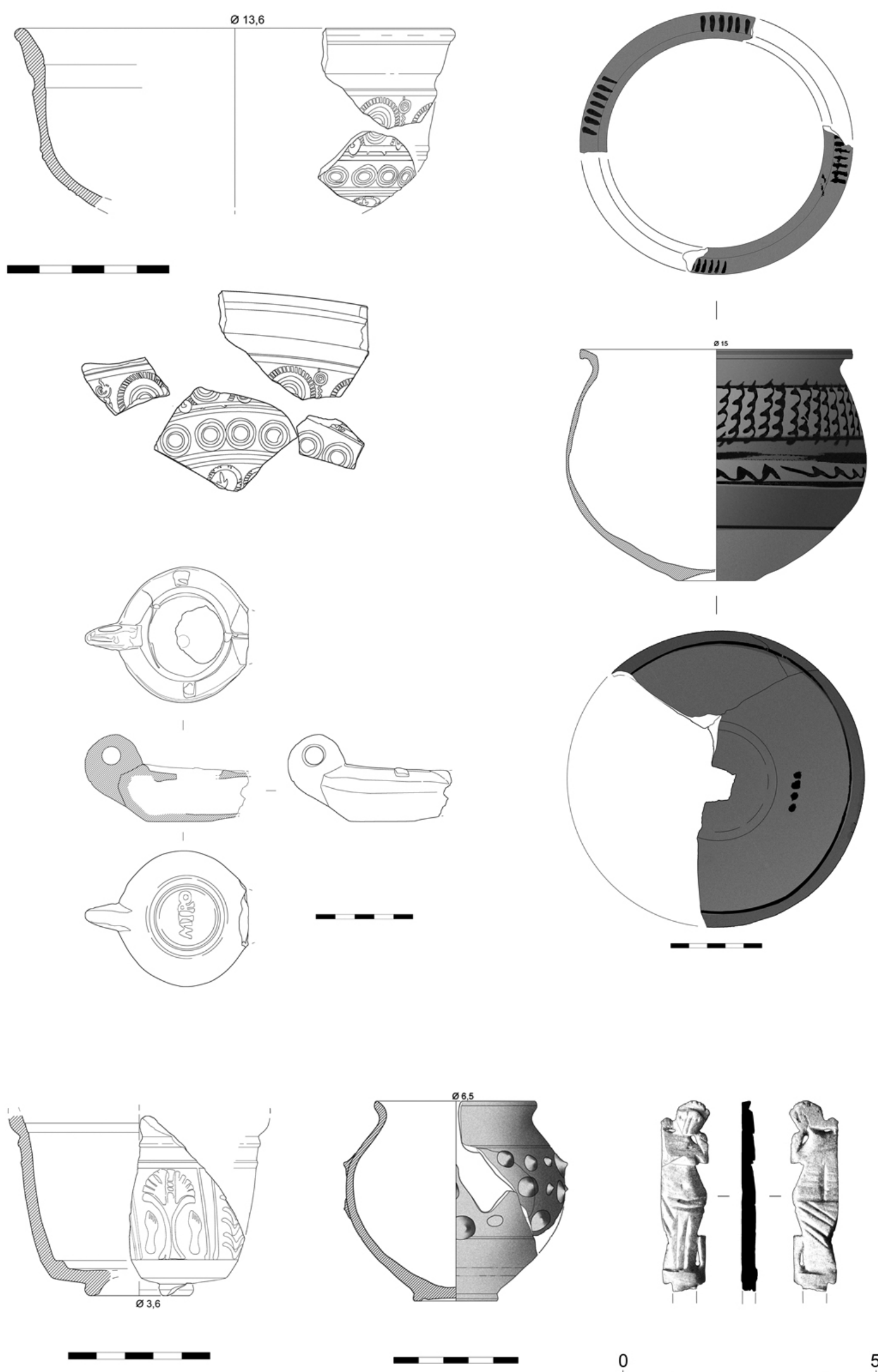

0

$\Delta$ Figura 2. Algunos materiales asociados al relleno de sondeo de extracción de áridos de la Fase 1 . De arriba a abajo y de izda. a dcha.: TSH (Drag. 37), lucerna de disco con firma MIRO, TSH (forma 30), cerámica pintada tipo "meseta Sur" (Forma 18); cubilete de paredes finas, acus crinalis. 
cerámicas grises ${ }^{12}$. Entre las producciones de cerámica común de cocina hemos diferenciado dos variantes; por un lado piezas globulares de gran tamaño utilizadas para el traslado de líquidos ${ }^{13} y$, por otro, las cerámicas utilizadas para la preparación y cocción de los alimentos ${ }^{14}$.

Hemos documentado varias lucernas de disco entre las que destaca una pieza completa del taller de MIRO. Se trata de una producción centroitálica, bien documentada en Hispania, y cuya cronología se ha establecido entre época neroniana y tardoflavia ${ }^{15}$.

Al margen del material cerámico brevemente descrito, queremos destacar la presencia de un As de acuñación local, en muy mal estado de conservación, así como un fragmento de la parte superior de un acus crinalis con la representación de Venus acicalándose los cabellos tras salir del baño ${ }^{16}$.

Todo el material recuperado en el relleno de este sondeo de peritación presenta una cronología bien definida que indica una colmatación producida en un único momento de la segunda mitad del siglo I d. C. La homogeneidad del vertido y los materiales arqueológicos recuperados nos inducen a pensar que el hiatus temporal entre la realización del pozo y su amortización debió ser casi inmediato. Las características del relleno permiten identificarlo como basurero, lo cual indica la existencia de una ocupación de la Vega Baja de Toledo desde, al menos, el siglo I d. C. La inexistencia de estructuras asociables a este momento en la parcela R3 nos impide concretar el tipo de hábitat asociado a este momento.
No obstante, cabe destacar que contextos cerámicos similares han sido documentados en distintos puntos de la ciudad de Toledo, no apareciendo asociados tampoco, hasta donde tenemos noticia, a elementos estructurales ${ }^{17}$.

También a una fase altoimperial, aunque en este caso indeterminada, podemos vincular una pequeña fosa localizada al oeste del sondeo de peritación ya descrito. Se trata de una fosa de forma casi circular de c. $3 \mathrm{~m}$. de diámetro y $40 \mathrm{~cm}$. de profundidad. El material asociado al relleno de esta fosa es poco significativo, pudiendo destacar tan sólo su adscripción romana altoimperial dada la presencia de cerámica pintada tipo "Meseta Sur" cuya producción no va más allá de mediados del siglo II d. C. (Abascal 1986), además de cerámica romana pintada y común de cocina. Esta fosa es cortada por la construcción de un muro que asociados a la segunda fase de ocupación del yacimiento (vid infra).

\section{Fase 2. Siglo III-primera mitad del IV d. C. (fig. 3)}

A un segundo momento de ocupación en la R3 podemos vincular la instalación de una zona de extracción de áridos documentada en la mitad meridional de la parcela, así como una serie de estructuras -cubeta y cimentaciones murarias- que pudieron formar parte de una zona industrial de fabricación de material latericio y/o cerámico ${ }^{18}$. Aunque no existe una relación estratigráfica entre la cubeta, las cimentaciones murarias y las fosas de extraccción, podemos conectarlas

$\left({ }^{12}\right)$ En este caso, se trata de cerámica a torno, de cocción reductora, pastas muy decantadas de color grisáceo y engobes al exterior de color gris ligeramente más oscuros que las pastas, bien acabadas al exterior. Se trata de formas eminentemente cerradas (botellas y jarros) aunque también aparecen formas abiertas (platos).

${ }^{(13)}$ Se trata de piezas realizadas a torno, de cocción oxidante, con acabados engobados de color oscuro no uniforme, de pastas claras, formas globulares cerradas de gran tamaño (cántaros, jarras).

(14) Se trata de piezas realizadas a torno, de pastas toscas, con desgrasantes medios y gruesos. Aunque mayoritariamente de cocción oxidante, hay algunos ejemplos de cocciones reductoras y mixtas. Se trata de formas generalmente cerradas de perfil globular (ollas, ollitas, cazuelas, tapaderas, etc.) con evidencias de haber estado al fuego. En este grupo se engloban también los morteros.

(15) Balil 1968-1969: 174; Bailey 1980: 98; Rodríguez Martín y Alonso 2005: 48.

${ }^{16}$ Hemos documentado dos paralelos directos; uno de ellos en la pieza no de inventario 11647 del Museo Nazionale di Archeologia de Nápoles, mientras el otro se encuentra expuesto en el Museo Provincial de Cádiz. Se trata de piezas comercializadas durante la primera mitad del siglo I d.C.

$\left({ }^{17}\right)$ Las excavaciones realizadas en distintos sectores de la ciudad de Toledo, nos permiten conocer diversos contextos datables en la primera mitad del siglo I d. C. Así, la intervención arqueológica realizada en 1981 en el solar ocupado por el circo romano, deparó el hallazgo de un nivel anterior a la propia construcción del edificio de espectáculos que, datado durante la primera mitad del siglo I d.C., se caracterizaba por la presencia relativamente abundante de Terra Sigillata Itálica de época tardia y Terra Sigillata Sudgálica de los primeros momentos. Los autores fechan este momento de ocupación romana de la zona previa a la construcción del circo en los primeros años del emperador Claudio. Junto a este material se hallaron cerámicas comunes (ollas, cuenco, morteros, fuentes) que avalan esta cronología y que permiten afirmar que esta primera ocupación romana de la zona no fue ocasional o esporádica; aunque a ella no se haya vinculado ninguna estructura. Es éste el horizonte cronológico afectado por la construcción del circo a mediados del siglo I d. C. (60-70 d.C.Nespasiano) (Sánchez Palencia, Sáinz Pascual y Juan Garcia 1988). Por otra parte, la excavación arqueológica desarrollada en 1992 en el Paseo de la Basilica bajo la dirección de J. Garcia Sánchez de Pedro, permitió documentar un interesante conjunto de material adscribible al siglo I d.C. (García Sánchez 1996; Garcia Sánchez y Gómez García 2005). Se trata de un grupo cerámico compuesto por cerámicas pintadas del tipo "Meseta Sur". Las piezas, que aparecieron fuera de su contexto originario -formando parte como ripio de un muro de tapial de época visigoda- parecen proceder de un testar situado en las inmediaciones del lugar de hallazgo. Los autores proponen la existencia de un taller de fabricación de cerámicas pintadas tipo Meseta Sur en la propia Toledo al que cabría vincular los conjuntos cerámicos hallados en el Mercado de Abastos (Carrobles y Rodríguez Montero 1988; Carrobles 1987) y en los recientes sondeos de la Puerta del Sol (Tsiolis, 2005). En este último se ha hallado un conjunto cerrado de materiales fechables fundamentalmente en el tercer cuarto del siglo I d. C., si bien existen fragmentos atribuibles a época julio-claudia y otros de la segunda mitad del I d. C. En este conjunto se hallan fragmentos de TSI, TSG del taller de Grauffesenque, TSH, paredes finas, cerámica pintada Meseta Sur, cerámica gris de imitación con decoración de lúnulas (probablemente complutense) e imitaciones de paredes finas (Tsiolis 2005). Un contexto cerámico muy similar al documentado en la Puerta del Sol fue hallado durante las excavaciones desarrolladas en la Calle Real 4-8 durante los años 2000 y 2002 (Fernández del Cerro 2005). Aquí, la excavación de un sondeo proporcionó unos niveles del siglo l d. C. no alterados por las construcciones y ocupación posterior de la zona.

${ }^{(18)}$ En este sentido debemos señalar la presencia, a escasos metros al noroeste de la parcela R3, de un horno destinado a la cocción cerámica que se fecha, por arqueomagnetismo, entre el 115 y $415 \mathrm{~d}$. C. y que debió formar parte de este mismo complejo productivo. Véase Rojas y Gómez Laguna 2009. 


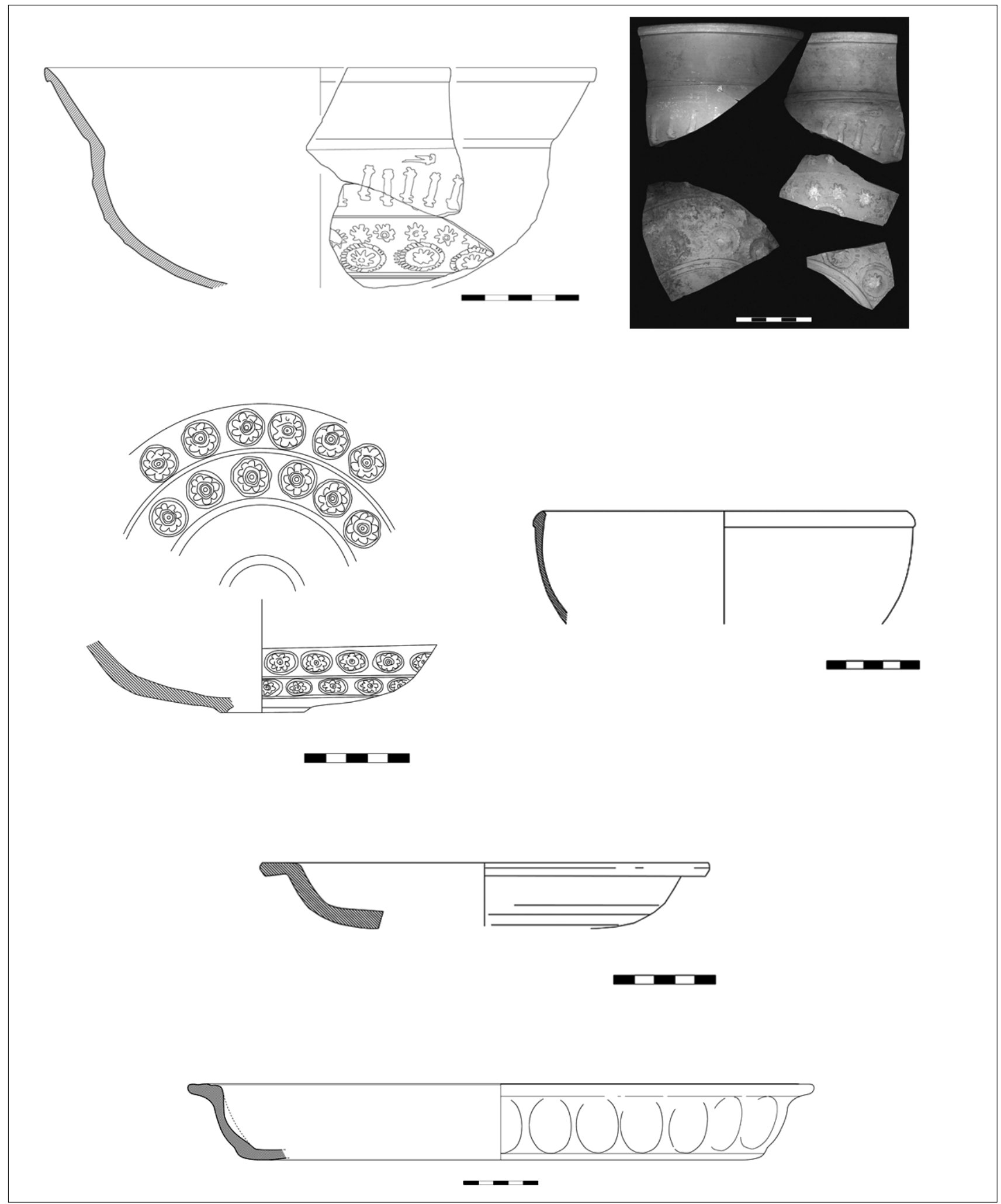

$\Delta$ Figura 3. Algunos materiales asociados a la Fase 2. De arriba a abajo y de izda. a dcha.: TSHT (forma 37t), TSHT (forma 37t), plato de engobe rojo, TSHT (Ritt. 8), TSHT (Palol 4).

cronológicamente en función de los materiales arqueológicos asociados a la colmatación y amortización de cada una de ellas.

Esta posible instalación de extracción y transformación de áridos estuvo formada, como apuntamos, por unas es- tructuras entre las que se encuentra una cubeta y el ángulo suroeste de una estancia. La cubeta es de planta rectangu$\operatorname{lar}(0,74 \times 1,01 \mathrm{~m})$ con una altura conservada de apenas 14 $\mathrm{cm}$. Su interior presenta doble revestimiento de opus signi- 
num con moldura de cuarto de bocel en los ángulos para asegurar la estanqueidad. Presenta un pocillo de limpieza circular en el centro del fondo, de $52 \mathrm{~cm}$ de diámetro y $8 \mathrm{~cm}$ de profundidad. Este depósito, debido a la localización y orientación que presenta, puede vincularse con las dos cimentaciones murarias mencionadas. Estos muros, como hemos apuntado, delimitarian por su flanco suroeste un espacio de dimensiones desconocidas y que pudo haber englobado en su interior la cubeta aludida. De este modo, y aunque su estado de conservación no nos permite concretar su función específica, podríamos vincularla con una estructura destinada a la decantación de los limos extraídos en las fosas de extracción documentadas en la zona sur de la parcela. A este complejo industrial cabe asociar también el horno para fabricación cerámica documentado en el vial adyacente ${ }^{19}$. Desde el punto de vista cronológico, la construcción de los muros que constituyen el límite suroeste de la sala que alberga la cubeta, se produjo con posterioridad a la colmatación de una fosa rellenada en época altoimperial, en un momento no posterior a mediados del s. II d. C. Es este el único indicio cronológico con el que contamos para fechar el inicio de este complejo productivo que, necesariamente, debe haberse iniciado con posterioridad a esta fecha.

A la extracción de áridos localizada al sur de estas estructuras podemos asociar tres fosas de extracción. Los límites de la más antigua no han podido ser delimitados debido a la presencia de estructuras posteriores sobre ella. Tan sólo hemos podido determinar parcialmente su límite norte y noroeste y constatar su continuidad hacia la zona meridional de la parcela R3, hecho probado por la existencia de fragmentos cerámicos de la misma pieza documentados a más $18 \mathrm{~m}$ de distancia. Nos hallamos, por tanto, ante una extracción de, al menos, $150 \mathrm{~m}^{2}$ y c. $300 \mathrm{~m}^{3}$. Junto a esta gran fosa, hemos detectado otras dos fosas de menor tamaño -una situada al norte de $5,6 \times 3,6 \times 0,4 \mathrm{~m}$ y c. $7 \mathrm{~m}^{3}$ y la segunda situada al oeste de c. 2,5 $\mathrm{m}$ de diámetro y 0,6 $\mathrm{m}$ de profundidad-que pertenecen al mismo horizonte cronológico.

Los materiales de relleno de las tres fosas adscritas a este momento permiten considerar su colmatación en un mismo momento cronológico datable entre la segunda mitad del siglo III d.C. y el primer cuarto del siglo IV d. C. ${ }^{20}$. En este estudio preliminar podemos destacar la presencia de un importante conjunto de TSHT, así como de cerámica común romana. Las sigillatas de estos rellenos son mayoritariamente formas lisas, en esencia cuencos Ritt. 8 aunque está también presente la forma Ludowici Tb. Es también destacable la presencia de piezas decoradas -formas $37 t$ y $29 t-a$ base de los motivos típicos del denominado estilo "Corella" o primer estilo tardío basado en frisos de rosetas y de círculos concéntricos, bastoncillos o motivos verticales y rosetas simples 0 enmarcadas en círculos ${ }^{21}$. Los rellenos de estas fosas presentan también, como hemos mencionado, una gran cantidad de cerámica común, esencialmente de cocina ${ }^{22}$.

Esta extracción de áridos ${ }^{23}$ puede ser puesta en relación con el importante desarrollo constructivo atestiguado en esta zona suburbana de Toletum entre finales del siglo III e inicios del IV d.C., siendo ésta la materia prima empleada para la construcción del material constructivo requerido en las nuevas edificaciones ${ }^{24}$.

(19) Ver nota anterior.

$\left.{ }^{(20}\right)$ El abandono de la utilización de la cubeta podemos fecharlo en un momento post quem a 324 d.C. en función de la presencia, en el relleno que la colmataba, de un AE 3 del periodo de corregencia de Constantino I y Licinio (308-324).

${ }^{(21)}$ Los motivos decorativos atestiguados son muy similares a los documentados en el Mercado de Abastos de Toledo (Carrobles y Rodríguez Montero 1988) aunque en nuestro conjunto cerámico están ausentes las decoraciones a base de grandes círculos concéntricos y tangentes trazados a compás y decoraciones con ruedecilla caracteristicos del tercer estilo de la TSHT que aparecen a partir del segundo tercio del siglo IV d.C. (Juan Tovar 2000: 89). Un conjunto cerámico similar al atestiguado en este relleno de la R3 lo hemos documentado recientemente en el yacimiento de Carranque (Toledo) en un contexto arqueológico cerrado y conformado por el relleno de una gran fosa de extracción al que se asocian gran cantidad de Ritt. 8 junto con otras formas lisas y un fragmento de 37 tardia con decoración estilo corella, estando ausentes las decoraciones de grandes circulos. Este relleno de Carranque podemos fecharlo, a partir de hallazgos numismáticos y relaciones estratigráficas, en un momento post quem 270 d. C. y ante quem mediados del siglo IV d.C. Estos dos conjuntos cerámicos permiten confirmar la presencia de la forma $37 t$ en contextos de la segunda mitad del siglo III-primer cuarto del siglo IV d.C. y la ausencia de decoraciones de grandes círculos en este periodo.

${ }^{22}$ S Se trata de un amplio conjunto cerámico mayoritariamente de cocción reductora, aunque también oxidante y mixta, de pastas toscas de color negro y grisáceo, con desgrasantes medios y gruesos. No presentan acabados exteriores. En su mayor parte se trata de formas globulares cerradas (ollas) con evidencias de fuego. Cabe destacar el gran número de fuentes y platos de engobe rojo-pompeyano de producción hispana. También hemos atestiguado un conjunto de cerámica común de mesa de cocción oxidante, pastas claras, desgrasantes medios y finos y acabados más cuidados al exterior que la de cocina, en algunos casos bruñidos. Las formas son cerradas, siendo las botellas y las jarras las piezas más numerosas

(23) Cabe destacar que, durante la excavación de 2004 y 2006, se documentaron numerosas fosas de extracción de arcillas bajo las construcciones visigodas (Rojas y Gómez Laguna 2009).

${ }^{24}$ Entre las construcciones romanas documentadas en este sector de la Vega Baja en época tardorromana, se encuentran los dos pavimentos musivos hallados en 1923 en los terrenos de la antigua Fábrica de armas, y pertenecientes a una importante villa instalada a orillas del Tajo. Conocidos y actualmente conservados en el Museo de Santa Cruz de Toledo, se trata del mosaico con escenas portuarias que pavimentó un espacio octogonal inscrito en una fuente y del mosaico con escena de peces que soló una amplia estancia rectangular de esta importante villa que gozó de un momento de esplendor a finales del siglo III o inicios del IV d. C., data otorgada para estos dos pavimentos musivos (San Román 1934; Balil 1961-62; Blázquez 1982: 33-36; Mélida 1923; Blázquez 1982: 36-40). Posiblemente en relación con este conjunto suburbano se halle el estanque documentado en las excavaciones desarrolladas en 1993 para la construcción de la Consejería de Obras Públicas (Rojas y Villa 1996). Por otro lado, en las recientes excavaciones realizadas en la Vega Baja, J. M. Rojas y A. J. Gómez Laguna han documentado un pequeño edificio balneario en funcionamiento hasta mediados del siglo $\mathrm{V} \mathrm{d}$. C. que los autores ponen en relación con una construcción doméstica situada en esta zona de la ciudad (Rojas y Gómez Laguna 2009). 


\section{3. ÉPOCA VISIGODA}

\section{Fase 3}

No hemos documentado evidencias arqueológicas de ocupación entre mediados del siglo IV -momento de amortización de la fase $2-$ y mediados del siglo VI d. C. Tras este hiatus contamos con nuevas evidencias de extracción de áridos datables en un momento indeterminado de la segunda mitad del siglo VI d. C. A esta nueva extracción pertenece una fosa cuyo margen meridional se halla fuera de los límites de la parcela R3. Se trata de una fosa cuyas dimensiones máximas documentadas son $7 \times 4,3 \mathrm{~m}$, siendo su profundidad 1,8 $\mathrm{m}$. Su relleno es homogéneo, con materiales de tradición claramente romana ${ }^{25}$, si bien están ausentes producciones hispánicas de sigillatas tardias y cerámicas de importación que permitieran datarlo en un horizonte tardorromano. Consideramos que este vertido se realizó en un momento visigodo temprano que hemos fijado, en función de cuestiones estratigráficas y a partir de la revisión de su material, en un momento indeterminado de la segunda mitad del siglo VI d. C.

La extracción de áridos de este momento debe ponerse en relación con la ampliación del tejido urbano de la ciudad más allá del encintado murario de época romana y la urbanización de sectores que hasta el momento se habían mantenido como zonas peri y suburbanas, coincidiendo con la instalación en Toledo de la sede definitiva del poder regio visigodo a partir del reinado de Atanagildo (555-557) y la construcción, desde este momento, de diversos edificios civiles y religiosos destinados a acoger la corte visigoda (vid. infra).

\section{Fases 4 y 5}

La amortización de esta fosa está relacionada con el inicio de la urbanización de todo este sector de la nueva ciudad visigoda atestiguada en la parcela R3 en las fases 4 y 5 . Estas fases se manifiestan con una intensa actividad constructiva, evidenciada en la mitad sur de nuestra parcela, y que se corresponde con la urbanización de la Vega Baja a raíz de la conversión de Toletum en Sede Regia a partir del reinado de Atanagildo (555-557) y la importante renovación edilicia acontecida en la capital visigoda a raíz de su elección como sede del III Concilio eclesiástico celebrado en el año 589 en el que se declaró oficialmente la conversión al catolicismo del rey Recaredo. Estos dos hechos, junto a la celebración de sucesivos concilios eclesiásticos en la capital visigoda hasta el año 694, supusieron una importante transformación urbanistica para la ciudad en la que se erigieron y transformaron construcciones religiosas y civiles que debían acoger una población, sin duda, acrecentada al calor de la intensa actividad económica y cultural ${ }^{26}$.

\section{Fase 4. Pre-urbanización}

Las evidencias constructivas de esta primera urbanización visigoda en la Parcela R-3 nos las aportan una serie de cimentaciones murarias situadas en el extremo sur y de las que apenas podemos aportar más datos que los de su mera erección con posterioridad a las fases tardorromana (Fase 2) y visigoda temprana (Fase 3) y con anterioridad a la Fase 5 a. Se trata de cinco tramos murarios, sin conexión entre ellos, que no permiten definir ningún espacio o estancia concreta. Para la construcción de uno de estos muros se empleó ma-

(25) Destaca la cerámica común de mesa, herencia de las producciones de mesa romana, siendo las formas atestiguadas ollitas, jarros, botellas y cuencos. Se trata de piezas realizadas a torno, de cocción exclusivamente oxidante, de pastas decantadas claras, ocres y anaranjadas. Las formas cerradas de paredes rectas las constituyen botellas y jarras con una y dos asas, de cuellos estrechos en los casos de las botellas que tienen asas de secciones rectangulares, acanaladas y que no sobre-elevan respecto al borde de la pieza. Hay algún ejemplo de cuenco y ollita de pequeño tamaño. Las bases son principalmente de perfil recto para las botellas, y de umbo para jarros y ollitas. Las piezas presentan líneas de torno muy marcadas al interior, siendo las superficies exteriores alisadas.

Dentro de este grupo, debemos mencionar la presencia de una producción de cerámica vidriada. Se trata de piezas de formas abiertas, de cocción oxidante o reductora, con pastas naranjas, marrones o negras y desgrasantes medios y gruesos. Estas piezas presentan vidriado de color verdoso muy craquelado tanto al interior -en capa uniforme y gruesa de hasta de $1 \mathrm{~mm}$ de grosor-como al exterior, en este caso menos grueso y también de color blanquecino.

Igualmente debemos destacar las producciones de cerámica común de cocina; realizadas a torno, también herencia de las formas romanas y con evidencias de fuego. Se trata, eminentemente, de formas cerradas formadas por ollas y orzas, con o sin asa que arrancan del borde de la pieza, bordes exvasados, apuntados, rectos y de sección almendrada. Las pastas son reductoras, con algunos ejemplos minoritarios de cocciones mixtas, sin presencia de cocciones oxidantes, con desgrasantes medios y gruesos. Los acabados son toscos al interior y al exterior.

${ }^{26)}$ Las excavaciones arqueológicas desarrolladas por J. M. Rojas y A. J. Gómez Laguna en el solar actualmente ocupado por la clínica Fremap calle San Pedro Verde n. ${ }^{\circ}$ 25-, permitieron poner al descubierto importantes cimentaciones correspondientes, según estos investigadores, a los palacios reales visigodos y a la Basilica de los Apóstoles dedicada a San Pedro y San Pablo (Rojas 2001), citada en numerosas ocasiones como sede de cinco de los diecisiete concilios eclesiásticos celebrados en la capital del reino visigodo (VIII, XII, XIII, XV y XVI celebrados en $653,681,683,688$ y 693 respectivamente). Esta iglesia, también conocida como praetoriensis, debió formar parte del centro aúlico al que cabe asociar el Palatium. En este sentido, las recientes excavaciones realizadas por estos mismos autores en el vial 1 han permitido documentar un edificio termal que, construido en la segunda mitad del siglo VI d. C., es posible vincular con este edificio palaciego (Rojas y Gómez Laguna 2009). Por otra parte, la elección de la capital visigoda como sede del III Concilio de Toledo en el que se declaraba al catolicismo como religión oficial (589), supuso también importantes transformaciones edilicias como nos menciona Juan de Biclaro, quien alude a la labor de Recaredo como fundador y benefactor de iglesias y monasterios "ecclesiarum et monasteriorum conditor et ditator efficitur", entre las que cabe también situar la construcción de la iglesia suburbana -apud Toletanam- de Santa Leocadia, sede de los concilios IV, V y XVII (633, 636 y 694 respectivamente) erigida sobre una iglesia martirial identificada con la localización actual del Cristo de la Vega, también en la Vega Baja (Palol 1991). La condición de la ciudad como sede regia supuso la construcción de numerosos edificios de carácter civil capaces, como han apuntado I. Velázquez y G. Ripoll, de sostener las necesidades espaciales del Aula Regia y del Officium Palatinum (Velázquez y Ripoll 2001: 546 y ss). Véase también Izquierdo 2006 y Balmaseda 2006. 
terial escultórico reaprovechado de algún edificio o monumento romano de las proximidades ${ }^{27}$.

\section{Fase 5}

Esta fase supone un gran cambio en la apariencia de la Vega Baja al producirse ahora la urbanización de este sector de la ciudad. A este momento pertenecen toda una serie de estructuras domésticas o habitacionales localizadas en la zona central y sur de la parcela R3 articuladas en función de un eje viario que atraviesa la parcela de este a oeste (Fase $5 a)$. Estas construcciones parecen ser objeto de puntuales reformas y reparaciones durante las fases $5 b$ y $5 c$ basadas en la elevación del nivel de circulación de todo el ámbito (tanto público como privado) y la reorganización interior de algunos de los espacios domésticos, reformas que parecen haberse producido en un corto lapso de tiempo, poniendo de relieve el gran dinamismo constructivo ya evidenciado en otros sectores de la Vega Baja ${ }^{28}$.

\section{Fase $5 a$ (fig. 4)}

En un único impulso constructivo se produce la urbanización de toda la mitad sur de la parcela R3 mediante la erección de una calle y de dos espacios domésticos surgidos a norte y sur del eje viario. Se trata de una vía de c. de $3 \mathrm{~m}$ de anchura empedrada con pequeños guijarros y que discurre de este a oeste, adaptándose, en cota, al leve desnivel existente en el terreno. Esta calle constituye el límite espacial para los dos núcleos domésticos documentados en nuestra parcela ${ }^{29}$.

\section{Núcleo doméstico sur (fig. 5)}

Al sur del eje viario se construyen ahora una serie de estructuras que englobamos bajo el epígrafe de núcleo doméstico Sur. Éste se halla enmarcado al norte por una cimentación muraria, de la que hemos documentado varios tramos, que discurre de este a oeste en paralelo a la vía. Este muro constituye la parte trasera de un ámbito doméstico desarrollado hacia el sur y del que conocemos, al menos, dos espacios bien definidos arquitectónicamente ( $\mathrm{A}$ y $\mathrm{B}$ ) articulados en función de lo que consideramos un patio a cielo abierto (C). El espacio más oriental ( $A$ ) es cuadrangular (4,3 $\mathrm{x}$ $2,7 \mathrm{~m}$ y $11,6 \mathrm{~m}^{2}$ ) y presenta un pavimento de tierra ${ }^{30}$. Al este de este ámbito se abre una nueva estancia (B) que apenas conocemos en parte, sin que hayamos documentado ningún suelo de uso asociado a ella. Al sur de ambos espacios (A y B) parece desarrollarse un patio (C) con pavimento de pequeños guijarros documentado en un tramo de 14,5 m de longitud máxima y 5,2 $\mathrm{m}$ de anchura máxima El límite sur de este patio lo forma un muro que discurre de este a oeste, configurando el extremo de un nuevo ambiente doméstico que se desarrolla al sur de la parcela R3 y que no conocemos.

\section{Núcleo doméstico norte}

Al norte de la calle se desarrolla un nuevo conjunto de estructuras cuyo límite meridional discurre en paralelo a la vía. Se trata de una serie de ambientes apenas documentados en algunos tramos de sus cimentaciones murarias. Existe, no obstante, un muro ${ }^{31}$ que marca un claro eje norte/sur, perpendicular al marcado por la calle, a cuyos lados se disponen

${ }^{(27)}$ Nos referimos a fragmentos tallados de mármol blanco de clara adscripción romana, si bien lo fragmentado de las piezas nos impide concretar a qué todo pertenecieron. La reutilización de material escultórico romano, entre el que se encuentran varios fragmentos de sarcófago figurado, en las estructuras murarias de época visigoda y emiral ha sido igualmente detectado en diversos sectores de la Vega Baja (Rojas y Gómez Laguna 2009)

${ }^{(28)}$ Fenómenos similares a los atestiguados en R3 han sido documentados en el resto de la zona intervenida de la Vega Baja durante los años 2005 y 2006 y recientemente publicados (Rojas y Gómez Laguna 2009).

${ }^{(29)}$ Las excavaciones llevadas a cabo por J. M. Rojas y J. A. Gómez Laguna han permitido documentar seis de las calles que conformaron la primera retícula de urbanización de la ciudad visigoda en la Vega Baja. Se trata, como en el caso de la vía detectada en la parcela R3, de ejes viarios de 3 metros de anchura, delimitadas por grandes calzos laterales y pavimentadas con cantos y gravas de pequeño tamaño y bien trabadas entre sí. Sólo una de las vías detectadas en esta fase ( $n^{\circ}$ 17) alcanza una anchura de $6 \mathrm{~m}$. siendo sus calzos laterales también de mayor tamaño. En función de su orientación y sus caracteristicas, J. M. Rojas y J. A. Gómez Laguna proponen que se trata de la via que comunicaba el complejo palatino con la Basílica de Sta. Leocadia y la propia urbs. En un momento de la primera mitad del siglo VII se produjo, según estos investigadores, una reurbanización de este sector de la ciudad, realizando una nueva retícula que, en parte, reaprovecha la anterior y que cabe vincular con la construcción de los grandes edificios civiles y religiosos de la capital del reino visigodo (Rojas y Gómez Laguna 2009).

${ }^{(30)}$ El material asociado a este suelo de uso es ciertamente escaso y poco significativo. Sigue la tradición tardorromana de cerámicas comunes y de mesa y, por posición estratigráfica, la situamos en un momento posterior al relleno de la fosa de la fase 3 que hemos datado en un momento indeterminado de la segunda mitad del siglo VI d. C.

(31) En la construcción de este muro se reutilizó material epigráfico procedente de una necrópolis romana cercana que, ya en este momento, estaría parcial o totalmente abandonada. Nos referimos a una estela funeraria que puede ser datada entre los siglos I a III d.C. De la estela, realizada en piedra caliza blanca, conservamos dos fragmentos que permiten conocer su texto integro a falta de su extremo superior derecho que no ha sido conservado. Presenta el campo epigráfico delimitado por un listón de $3 \mathrm{~cm}$. decorado con un tosco motivo de espiga inciso; decoración apenas conservada en el flanco izquierdo de la pieza. El campo se conserva íntegro a falta, como decimos, de la parte superior derecha, y está formado por cuatro líneas en las que se desarrolla el texto realizado en letras capitales cuadratas ejecutadas de manera muy tosca y sin guardar línea. Aparece un punto circular de interpunción detrás de cada palabra que parecen haber sido realizados una vez concluido el texto, como podría evidenciar la interpunción inclusa en la C. D[IIS]:M[ANIBUS SACRUM]

FOR[TUNA]

TA.HIC.S[ITA].

EST:S[IT]·T[IBI]·T[ERRA]·L[EVIS].

Traducción: Consagrada a los Dioses Manes/ Fortuna/ta Aqui yace/ Que la tierra te sea leve. 


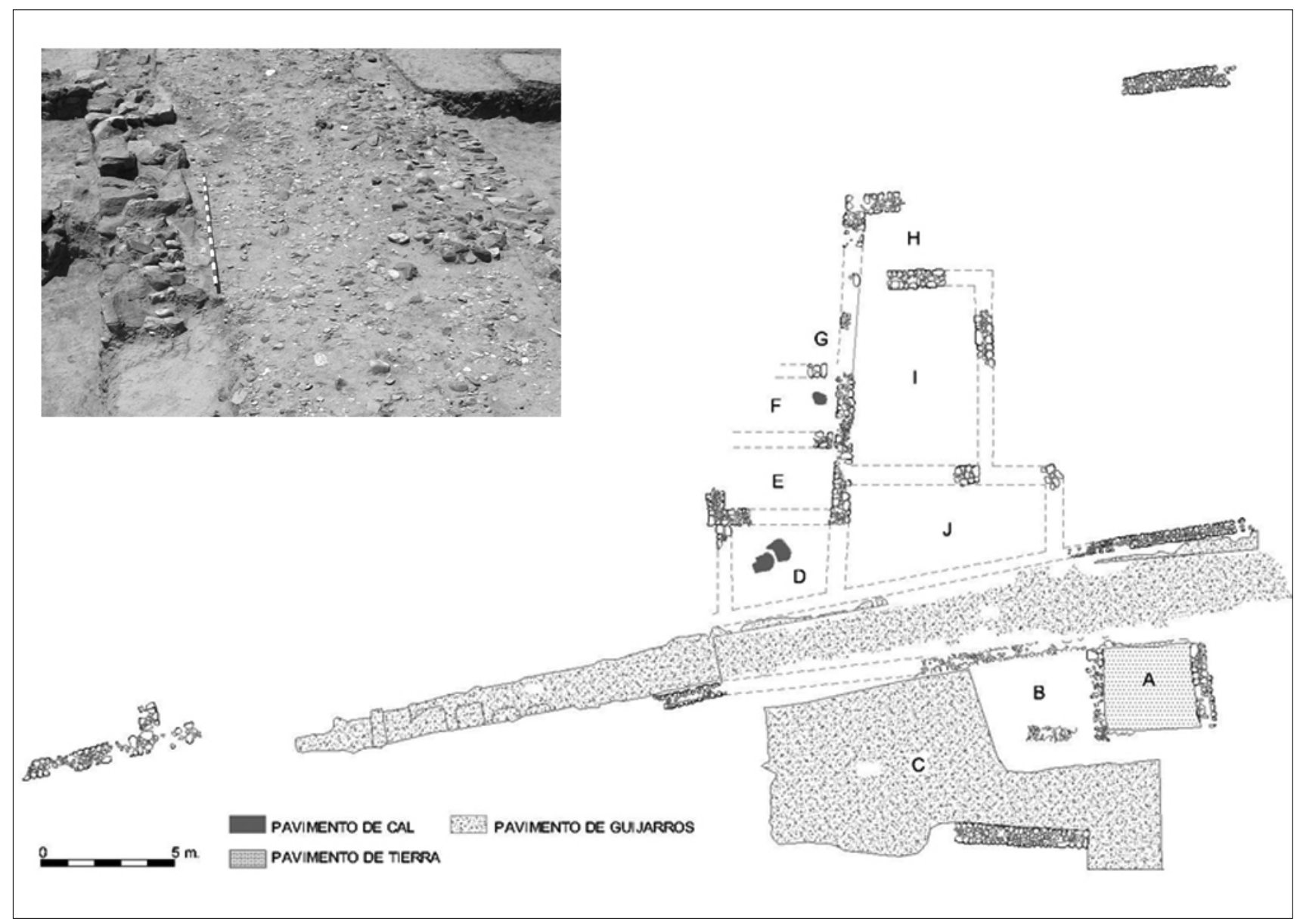

A Figura 4. Estructuras del urbanismo visigodo en la Fase 5a.

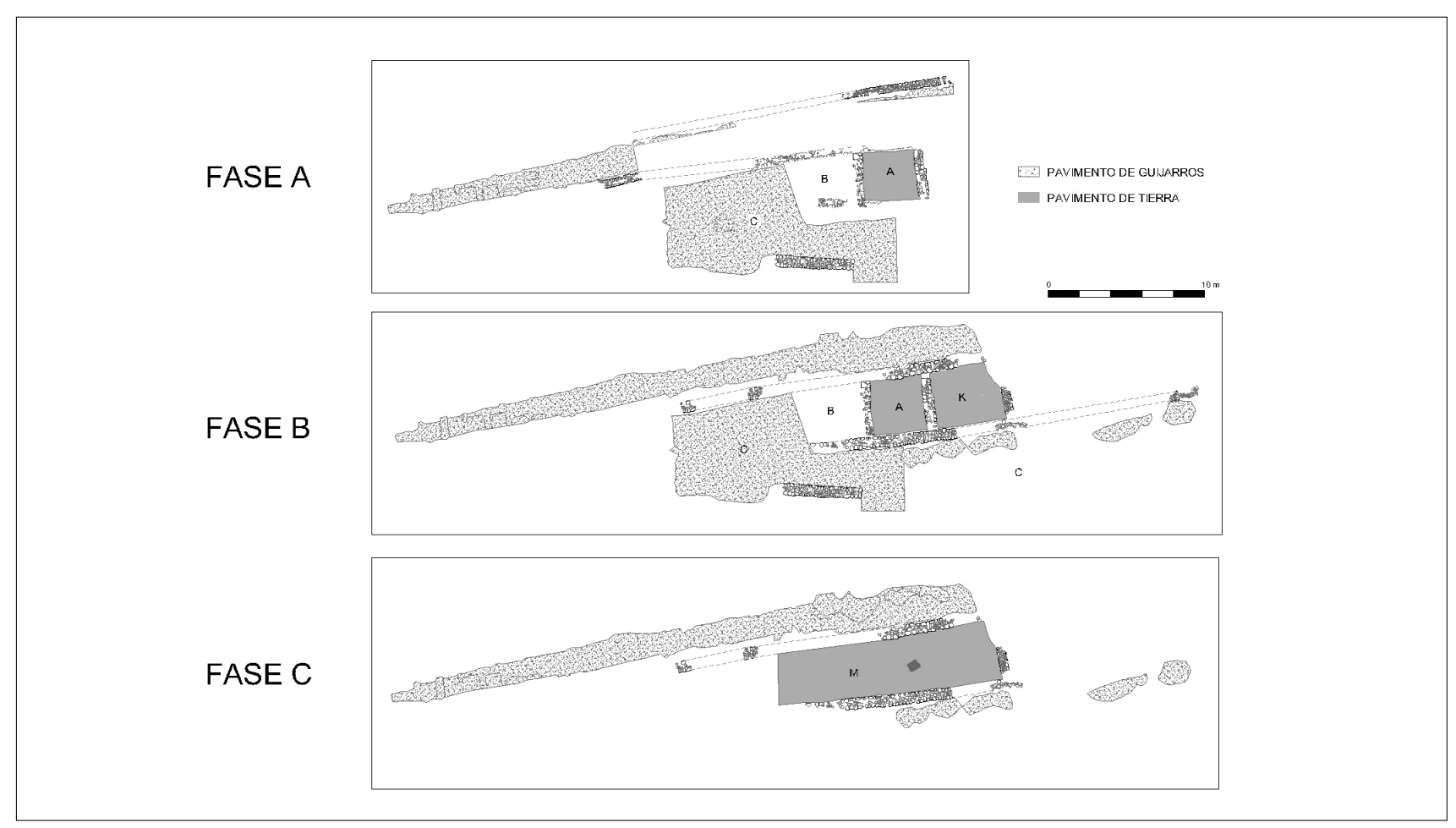

- Figura 5. Evolución del núcleo doméstico sur en las Fases 5a, 5b y 5c. 
varias dependencias. Al oeste hemos identificado, al menos, cuatro ámbitos ( $D, E, F$ y $G$ ). Del espacio más meridional (D) apenas conocemos un pequeño tramo de la cimentación muraria de sus límites oeste y norte, si bien conocemos parte de su pavimentación realizada con un solado de cal hallado en muy mal estado de conservación. Al norte del espacio D se halla una nueva dependencia (E), de planta rectangular $(4 \times 2,3 \mathrm{~m})$, y de la que no se han conservado suelos de uso o pavimentos. Al norte se abre el ámbito $F$, también de planta rectangular, del que conocemos parte de su pavimento -apenas $50 \times 30 \mathrm{~cm}$ - también realizado con mortero de cal. Al norte de este espacio $F$ se dispone el ámbito $G$, también rectangular y del que apenas documentamos un pequeño tramo de sus límites este y sur.

Al este del muro que marca el eje de distribución del núcleo doméstico norte, se disponen, al menos, tres espacios $(\mathrm{H}, \mathrm{I}$ y J) de los que no hemos documentado suelos de uso ni

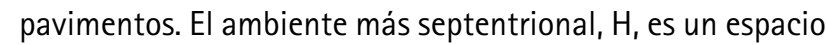
rectangular. Al sur, se abre el ambiente I, de mayores dimensiones que el anterior y del que conocemos todos sus límites $(6,7 \times 4,65 \mathrm{~m})$. Por último se halla el espacio J del que apenas conocemos parte de sus límites oeste, norte y este, siendo la calle necesariamente su límite meridional (7,3 $\mathrm{x}$ $3,2 \mathrm{~m})$.

A pesar de la parcialidad con la que conocemos las dependencias que conformaron estos núcleos domésticos, queremos destacar la uniformidad arquitectónica que presentan y que parece responder a la repetición de un módulo concreto que, a tenor de las reformas evidenciadas en las fases $5 b$ y $5 c$, parece responder satisfactoriamente a las necesidades de sus ocupantes. La presencia, en el núcleo sur, del patio (C) como elemento articulador del espacio doméstico, puede ayudarnos a comprender el modelo arquitectónico que rige esta urbanización ex novo producida en un momento no bien determinado de finales del siglo VI o inicios del VII d. C. coincidiendo, como ya hemos apuntado, con las grandes transformaciones urbanísticas y edilicias surgidas tras la instalación en Totetum de la Sede Regia del reino visigodo (555-557) y la celebración continuada de concilios eclesiásticos en sus iglesias desde el año 589 hasta el 694 (del III al XVII respectivamente).

Desde el punto de vista cronológico, los datos aportados por los trabajos de excavación apenas nos permiten establecer dataciones relativas en función de las propias relaciones estratigráficas entre las unidades estratigráficas documentadas. Así, sabemos que tanto el núcleo habitacional norte como el sur se asientan sobre un potente nivel que sella los rellenos de las grandes fosas de extracción romana (Fase 2) y visigoda (Fase 3) y que, creemos, pudo formarse a finales del siglo VI o inicios del VII d. C. para facilitar la urbanización de todo este sector mediante el vertido de un nivel homogéneo y sólido en el que asentar las nuevas construcciones. Los materiales asociados a este nivel de sellado son, no obstante, escasos y poco significativos.

\section{Fase $5 b$}

En un momento posterior a la fase 5 a se producen una serie de cambios que afectan tanto al eje viario, ahora repavimentado y recrecido su nivel de circulación, como al núcleo doméstico sur.

La calle es ahora repavimentada mediante la instalación de un nuevo pavimento de guijarros que eleva el nivel de circulación en 16/22 cm respecto al anterior, manteniéndose el leve desnivel de la vía que buza de oeste a este en torno a $0,40 \mathrm{~m}$.

\section{El núcleo doméstico sur (fig. 5)}

La fase $5 b$ se manifiesta en el complejo sur mediante la reconstrucción, desde nivel de cimentación, del muro colindante con la calle que mantiene, no obstante, la anchura y orientación del precedente. También se rehace, desde cimentación, el muro que limitaba los espacios $A$ y $B$ en su flanco sur que, en esta nueva fase, mantiene también la anchura y orientación del anterior. Junto a esta importante reforma estructural cuyo motivo se nos escapa, asistimos a una continuidad de los espacios ya existentes ( $A$ y $B$ ) cuyos muros delimitadores se mantienen intactos desde la fase precedente. El espacio A mantiene, por tanto, sus dimensiones a pesar de haberse rehecho sus muros norte y sur produciéndose ahora una repavimentación de la estancia con un nuevo suelo de tierra. Al este continua vigente el espacio B cuyas novedades radican también en la reconstrucción de sus límites norte y sur. En esta fase $5 b$ asistimos a la formación de un nuevo ambiente al oeste de $A$, espacio $K(4,4 \times 4 \mathrm{~m})$, que es también pavimentado por un suelo de tierra. Este conjunto de estancias siguen vinculadas al patio $C$ ya presente en la fase anterior. No obstante, el recrecimiento de los niveles de circulación evidenciados tanto en la calle como en los suelos de uso del espacio A motivó la repavimentación de este espacio a cielo abierto mediante la instalación de un nuevo pavimento de guijarros colocado directamente sobre el anterior.

Resulta evidente, a tenor de la observación de estas transformaciones, que los cambios, aunque profundos en algunos casos, no fueron realizados para reorganizar el espacio previo sino para mantenerlo tal cual, erigiéndose nuevos muros sobre los cimientos de los anteriores y recreciendo los niveles de circulación con nuevos pavimentos y suelos de uso. Desde el punto de vista cronológico apenas contamos con los materiales cerámicos procedentes de uno de los suelos de uso que, muy similares a los de la fase previa, pueden datarse en un momento indeterminado entre finales del VI y mediados del VII d.C. Precisamente esta similitud en los tipos cerámicos son los que nos permiten suponer que el hiato temporal producido entre la primera y segunda pavimentación del espacio A no debió ser muy dilatado.

Existen una serie de elementos localizados al norte de la calle que podrían relacionarse con nuevas reformas aconte- 
cidas en este sector de la parcela, si bien carecemos de datos estratigráficos que nos permitan ubicar su construcción en un momento coetáneo a los cambios acontecidos en la zona sur de la calle. Anulados, creemos, los antiguos espacios D a $J$, constatamos la construcción de un nuevo espacio rectangular, L, solado con un pavimento de guijarros. Quizás a esta fase $5 b$ sea posible asociar también dos cimentaciones murarias situadas al sur de este nuevo espacio, circunstancia tan sólo probable al aparecer ambas totalmente descontextualizadas. También a este momento indeterminado del desarrollo de la zona norte de la calle pertenece un pavimento de guijarros, documentado en varios tramos, que amortiza los muros que delimitaban las estancias del núcleo doméstico norte en la fase 5a. Supone, por tanto, esta reforma, la anulación del núcleo doméstico norte como se había mantenido hasta este momento, sin que hayamos documentado ninguna otra estructura asociable a la continuidad habitacional de este sector norte de la calle.

\section{Fase 5c}

Hemos documentado una nueva repavimentación de la calle, detectada en un tramo máximo de $8,8 \mathrm{~m}$ y que supone una sobreelevación de apenas $10 \mathrm{~cm}$ sobre el anterior pavimento. Al igual que habiamos detectado en las pavimentaciones previas de la vía, este nuevo solado presenta un leve buzamiento este/oeste que en el tramo detectado es de $10 \mathrm{~cm}$.

\section{Núcleo doméstico sur (fig. 5)}

De nuevo hemos documentado una serie de cambios que afectan a la organización arquitectónica del complejo sur. En este momento asistimos a un cambio en la estructura de este núcleo al desaparecer las compartimentaciones de los espacios $A, B$ y $K$ que son convertidos en una sola dependencia, $M$, pavimentada por un suelo de tierra. El nuevo espacio surgido es de planta rectangular y grandes dimensiones
(3,6 m x, al menos, 19,85 m de longitud), instalándose en su interior un hogar cuadrado $(57 \times 43 \mathrm{~cm})$ construido con material latericio. Este nuevo espacio doméstico sigue articulado en función del patio $C$ que se mantiene vigente al igual que la calle que discurre al norte del nuevo gran espacio ahora creado. Desde el punto de vista cronológico, creemos que esta nueva reforma puede ser datada en un momento indeterminado de la primera mitad del siglo VII d. C., existiendo, ahora sí, algunos indicios que nos permiten avanzar en el tiempo respecto a los materiales de los suelos de uso de las fases precedentes ${ }^{32}$.

\section{Fase 6 (fig. 6)}

Estas evidencias del abandono habitacional del núcleo norte parecen confirmar la transformación de este sector de la Vega Baja en una nueva cantera de explotación de áridos a partir de la fase 6 . Esta reducción del espacio urbano hacia el sur de la Vega Baja ha sido igualmente documentada en otros sectores del yacimiento ${ }^{33}$.

Como decimos, este abandono del hábitat atestiguado en la R3, al menos de forma parcial, parece corresponderse con la apertura de nuevas fosas de extracción de áridos localizadas en la zona central de la parcela. Se trata de un conjunto de fosas de formas y tamaños diversos que se cortan y solapan unas a otras y que parecen evidenciar una actividad extractiva de poca envergadura (fig. 6). Estas fosas fueron convertidas en basurero como evidencian los materiales que forman parte de los rellenos que las colmatan. El análisis de los materiales que conforman estos rellenos nos permiten afirmar que la colmatación de las fosas se produjo en un momento visigodo avanzado, posterior a mediados del siglo VII d. C., existiendo diferencias substanciales con los materiales visigodos asociados a los suelos de uso de los espacios domésticos que hemos considerado de finales del siglo $\mathrm{VI} d$. $C$. a medidos del VII d. C. ${ }^{34}$ (fig. 7).

(32) Están ausentes las evidencias que hemos detectado en otras unidades relacionadas con el inicio de época emiral. Es, por tanto, un nivel de uso plenamente visigodo datable durante el siglo VII. No obstante, por comparación con los materiales documentados en el relleno de la fosa de extracción de la Fase 3 -de evidente tradición tardorromana-, y con los materiales de los suelos de uso de las fases $5 a$ y $5 b$, cabe datar este suelo de uso quizás en la primera mitad del siglo VII. Por comparación con los materiales de estos dos suelos de uso anteriores, cabe destacar que comienzan a aparecer algunos elementos que se alejan de la tradición tardorromana como son las botellas de cerámica común de mesa de pastas blanquecinas, la presencia de pequeños morteros de mármol y una cerámica con vedrío verde.

${ }^{(33)}$ Este retranqueo del núcleo habitacional hacia el sur del yacimiento ha sido atestiguado en diferentes parcelas como asi nos ha comunicado Antonio Gómez Laguna a quien agradecemos la información.

(34) La cerámica común de mesa está constituida por piezas realizadas a torno, principalmente formas cerradas para contener y transportar líquidos: cántaros de grandes asas, botellas de cuello largo y dos asas que arrancan del cuello de sección oval principalmente, jarras y jarros con picos vertederos y anchas asas de sección acanaladas, en dos casos jarros con pico vertedor tabicado con pitorro de gollete. También a este grupo podemos asociar algunos cuencos, cazuelas y ollas. Las bases son mayoritariamente de galleta con algún ejemplo ocasional de umbo. Se caracteriza este grupo por sus pastas claras, ocres, anaranjadas y naranjas, bien depuradas con desgrasantes finos. Las cocciones son oxidantes, existiendo algunos casos con pastas mixtas que son, no obstante, muy poco frecuentes. Las superficies exteriores son mayoritariamente alisadas, siendo muy evidentes las huellas de torno en el interior de muchas de las piezas. En dos casos se evidencian muestras de decoración a base de líneas incisas onduladas. Por su parte, la cerámica común de cocina está formada por piezas realizadas a torno, principalmente formas cerradas como ollas, jarros y cazuelas, con o sin asas que parten del borde con secciones mayoritariamente acanaladas y que no sobresalen de la línea de borde. La cocción es mayoritariamente reductora, si bien hay piezas de cocción oxidante con evidencias de fuego en la parte externa. Las pastas son grises, negruzcas y anaranjadas, no bien decantadas con desgrasantes medios que en ocasiones son gruesos. Las superficies externas no están muy cuidadas, si bien suelen tener un acabado alisado en el que, en ocasiones, se realizan ondulaciones que no levantan arcilla de la pieza. Las bases son planas. 


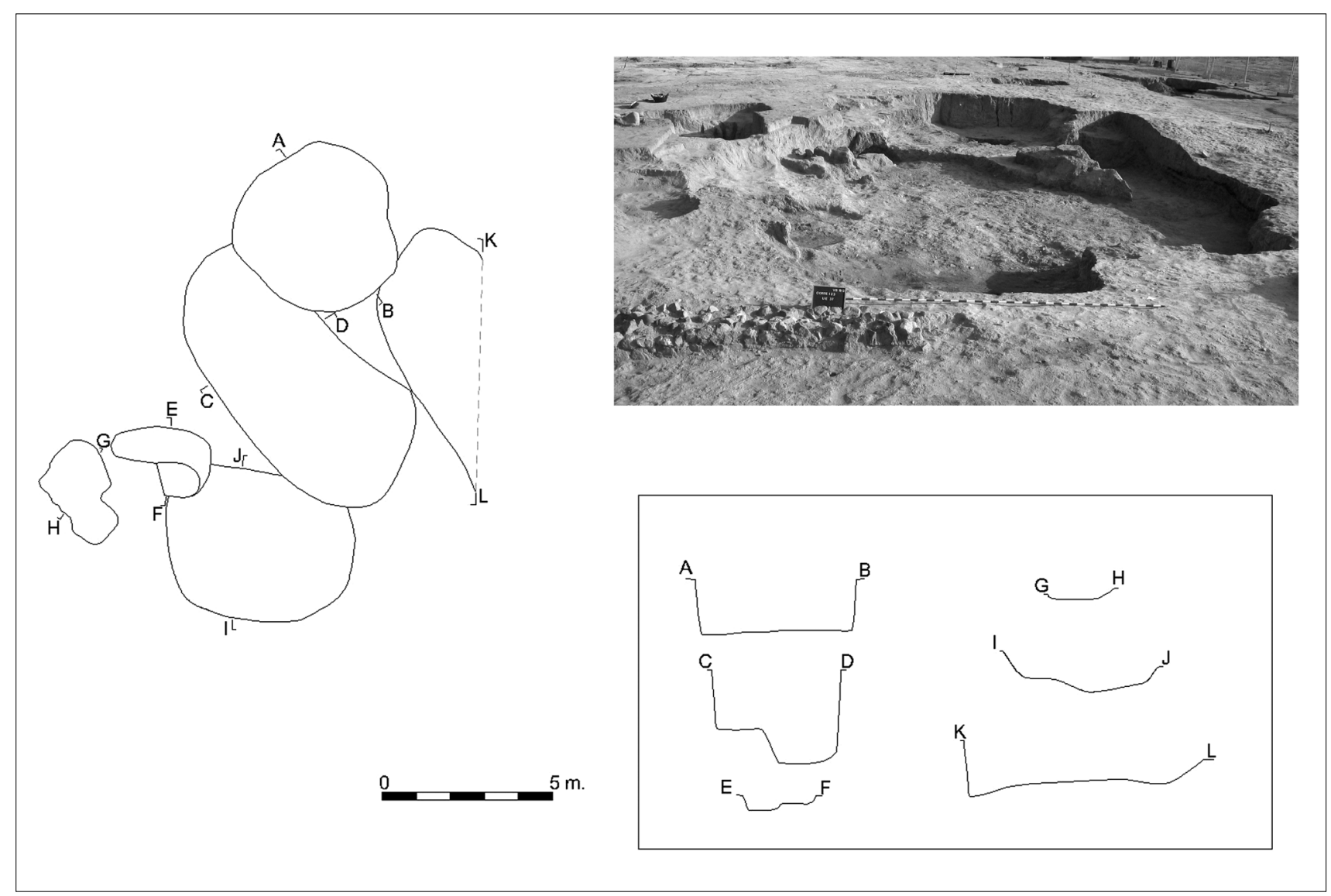

A Figura 6. Fotografía, planta y sección de las fosas de extracción de áridos de la Fase 6.

\section{4. ÉPOCA ISLÁMICA}

A la muerte de Witiza en el año 710 y la posterior elección de Rodrigo como nuevo monarca visigodo, sobrevino una guerra civil entre los partidarios de Rodrigo y los de Akhila, hijo de Witiza, que supuso una debilitación del poder visigodo acrecentada con el paso a la Península de las tropas de Tariq en el año 711 desde el norte de África. La derrota visigoda en la batalla del Guadalete fue decisiva y un año más tarde, en 712, Musa ibn Nusayr (Muza) gobernador de Ifriqiya ocupaba la capital del reino visigodo, Toledo. Se ponía así fin al reino visigodo y se iniciaba el control omeya de la Península. Aunque especialmente evidente para la arqueología a partir de época califal, la primera presencia emiral en Toledo se corresponde, entre otras transformaciones, con la instalación de una amplia necrópolis en la Vega ${ }^{35}$, espacio que, al igual que en época romana, compartió esta función con la de huerta.
Fase 7. Fase emiral temprana (fig. 8)

La extracción de áridos en la parcela R3 parece mantenerse durante la primera mitad del siglo VIII como parecen avalar dos fosas localizadas en el sector más septentrional de la parcela. Esta extracción, sin duda de mucha menor envergadura que las realizadas hasta ahora, queda espacialmente limitada al extremo norte de la misma donde se abren dos fosas de reducidas dimensiones $(7,10 \times 2,8 \times 0,65 \mathrm{~m}$ y 2,9 $\mathrm{m}$ de diámetro $\times 0,95 \mathrm{~m}$ de profundidad) cuya adscripción a las primeras décadas del siglo VIII y, por tanto, a época emiral temprana, viene dada por los materiales asociados a los rellenos que las colmatan. Aunque de tradición mayoritariamente visigoda, aparecen ahora ciertos elementos característicos de las primeras fases emirales, como los cuencos con pintura al exterior, las ollas con bordes muy exvasados y rectos, la presencia de carenas en la parte inferior de cuencos y ollas, asas sobreelevadas de los bordes de jarras y jarros y la aparición

(35) Junto a las ya conocidas inhumaciones emirales documentadas en el circo y en las proximidades de la Puerta de Visagra (Juan 1987; Maquedano et alii 2002 a y 2002b), las recientes intervenciones en la Vega Baja (Vial 12) han permitido localizar una necrópolis islámica de la que se han documentado 68 enterramientos y cuya cronología parece arrancar en el siglo VIII. Esta necrópolis estaría, según J. M. Rojas y A. J. Gómez Laguna, en relación con un hábitat disperso surgido en la Vega Baja en época emiral (Rojas y Gómez Laguna 2009). En este sentido, cabe señalar la localización en las recientes excavaciones de una serie de feluses acuñados en los primeros años de la invasión (Garcia Lerga, Gómez Laguna y Roja 2007). 


\section{FASE 3}
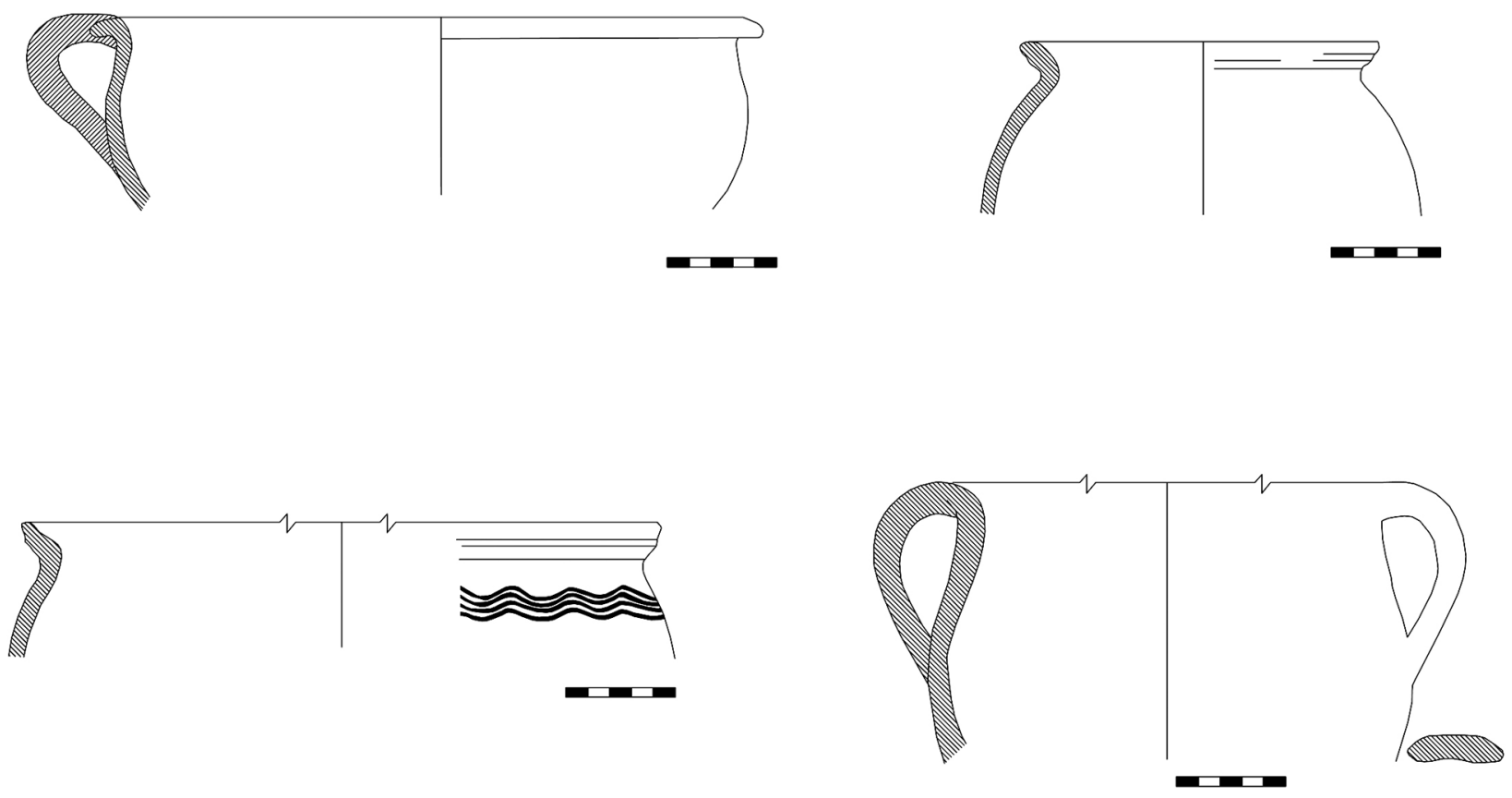

\section{FASE 6}
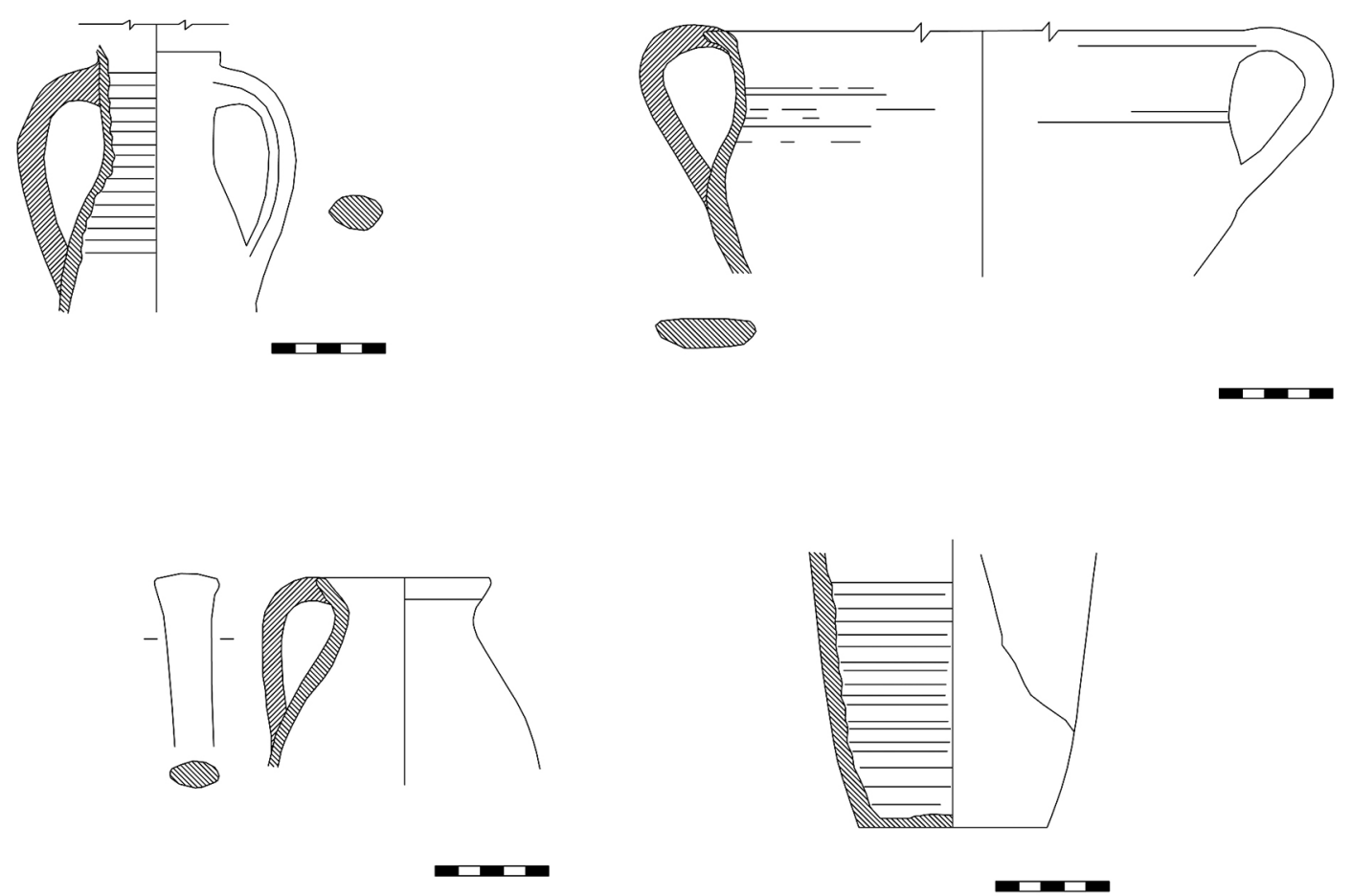

A Figura 7. Algunos materiales asociados a los rellenos de colmatación de las fosas extractivas de las Fases 3 y 6. 
de formas netamente islámicas como un fragmento de quemaperfume que avalan la cronología propuesta.

\section{Fase 8 (figs. 8 y 9)}

La siguiente fase atestiguada en la R3 se corresponde con la presencia de dos silos localizados en el extremo norte de la misma y la construcción de una noria en la mitad sur de R3, circunstancia que pone de manifiesto la conversión de la parcela en una zona de huerta, hecho por otra parte harto constatado por las fuentes escritas y la arqueología (Delgado Valero, 1987, 1991, 1999 y 2001). Los dos silos se hallan, como decimos, en el extremo norte de R3 a una distancia de apenas 0,62 $\mathrm{m}$ uno del otro. En ambos casos se trata pequeñas unidades negativas de planta circular $(1,20 \mathrm{~m}$ y $1,3 \mathrm{~m}$ de diámetro y 1,8 y $2 \mathrm{~m}$ de profundidad respectivamente) excavadas en el nivel geológico, si bien uno de ellos corta a una de las fosas de la fase precedente. La presencia de estos silos, que interpretamos como zona de almacenaje para productos de huerta, pudo estar relacionada con la construcción de la noria mencionada. En este caso, se trata de una caja de noria de forma ovalada con 2,4 m de longitud máxima (N/S) y $1 \mathrm{~m}$ de anchura máxima, realizada con sillares de piedra de mediano y gran tamaño ${ }^{36}$ (fig. 9).

Respecto a la cronología en la que esta zona de R3 se convierte en espacio de huerta, contamos con la data ante quem de los materiales procedentes de la colmatación de los silos y de la noria que presentan elementos plenamente emirales (vid infra).

\section{Fase 9}

La siguiente evidencia de ocupación atestiguada en R3 se corresponde, como apuntamos, con la amortización de los silos y la noria construidos en la fase anterior y parece estar en relación con el abandono de las actividades agrícolas al menos, como se habían mantenido hasta el momento. Los materiales asociados a estos niveles de amortización presentan características tipológicas unitarias ${ }^{37}$ en las que se hacen más evidentes que en las fases previas los elementos netamente islámicos -bordes muy sobre-elevados de cántaros o jarros, cuencos de bordes apuntados con pintura exterior $^{38}$, etc.-. También asociado al relleno de uno de los silos hemos documentado la presencia de un fragmento de cipo funerario islámico de sección circular, circunstancia que parece poner de relieve la reutilización de elementos procedentes de la necrópolis cercana.

\section{5. ÉPOCAS MODERNA Y CONTEMPORÁNEAS INDETERMINADAS}

\section{Fase 10}

Existen en toda la superficie de la parcela R3 una serie de materiales residuales y en posición secundaria, removidos por la acción del arado, que pueden ser datables en época moderna indeterminada ${ }^{39}$ (siglos XVI en adelante). No obstante, estos materiales se hallan descontextualizados y no se asocian a ninguna estructura que nos permita concretar el tipo de frecuentación o hábitat producido en la parcela durante estos siglos ${ }^{40}$.

\section{Fase 11}

En un momento de mediados del siglo XX se produjo una importante intervención en todo el flanco este de la parcela y que alteró todos los estratos y evidencias del asentamiento

${ }^{(36)}$ Entre los sillares que conforman la caja de la noria se hallan dos fragmentos escultóricos reutilizados de alguna construcción cercana. Uno de ellos es el fragmento de un elemento escultórico romano, quizás de uso funerario o coronamiento de un altar, que presenta decoración a base de una flor de ocho pétalos con botón central inscrita en un elemento sogueado. La segunda pieza es un fragmento escultórico visigodo, posiblemente un friso, de taller toledano y datable en el siglo VII decorado con un roleo vegetal con trifolia. Numerosos paralelos para esta última pieza en Barroso y Morín 2007.

(37) Se trata, esencialmente, de cerámica común de mesa, con abundante presencia de formas globulares de gran tamaño -tinajas y cántarosaunque también aparecen formas cerradas de paredes rectas tipo botella y cuenco. De cocción exclusivamente oxidante, las pastas son claras, ocres y blanquecinas, bien decantadas, con huellas de torno al interior. Las superficies presentan acabados cuidados, principalmente alisados aunque también, bruñidos. Algunas piezas, principalmente cuencos y cuencos de gran profundidad, presentan al exterior decoración pintada con trazos más o menos regularizados de colores oscuros -negros, marrones-. El porcentaje de cerámica común de cocina es ciertamente minoritario respecto a las cerámicas de mesa o finas. Realizadas a torno, de cocciones oxidantes y mixtas, no están presentes las cocciones reductoras que sí lo estaban en horizontes anteriores. Las pastas son anaranjadas al interior y oscuras al exterior, con desgrasantes medios y sin acabados cuidados en las superficies.

(38) C. Barrio y B. Maquedano documentaron en el Corralillo de San Miguel una fosa (Fosa 1) en cuyo relleno aparecen elementos cerámicos muy similares, en función de la descripción a las que conforman el relleno de los silos. Estos autores llaman la atención sobre la presencia de piezas carenadas, de pastas amarillentas y labios biselados al interior, con decoración a base de grandes pinceladas que forman meandros agrupados y realizados en color negro o rojizo. Los autores, que datan este contexto en época emiral, relacionan estas piezas con las analizadas por Y. Álvarez Delgado en Ercávica y que esta autora relaciona con las tribus bereberes presentes en la Peninsula en época emiral. Ver Barrio y Maquedano 1996 y y Álvarez Delgado 1989.

${ }^{(39)}$ La presencia de un cornado de Alfonso XI, aunque en posición secundaria, pone también de relieve la frecuentación de la zona durante el siglo XIV.

$\left.{ }^{40}\right)$ No obstante, no puede olvidarse que a finales del siglo XVIII y por orden de Carlos III, se construyó, a escasos metros de la parcela intervenida, la Real Fábrica de Armas de Toledo convertida, tras una serie de remodelaciones y adaptaciones a lo largo del siglo XIX y las primeras décadas del XX, en el actual campus universitario de la Universidad de Castilla-La Mancha. Véase al respecto, entre otros, Peris 1999 y Peris et alii 2003. 


\section{FASE 7}
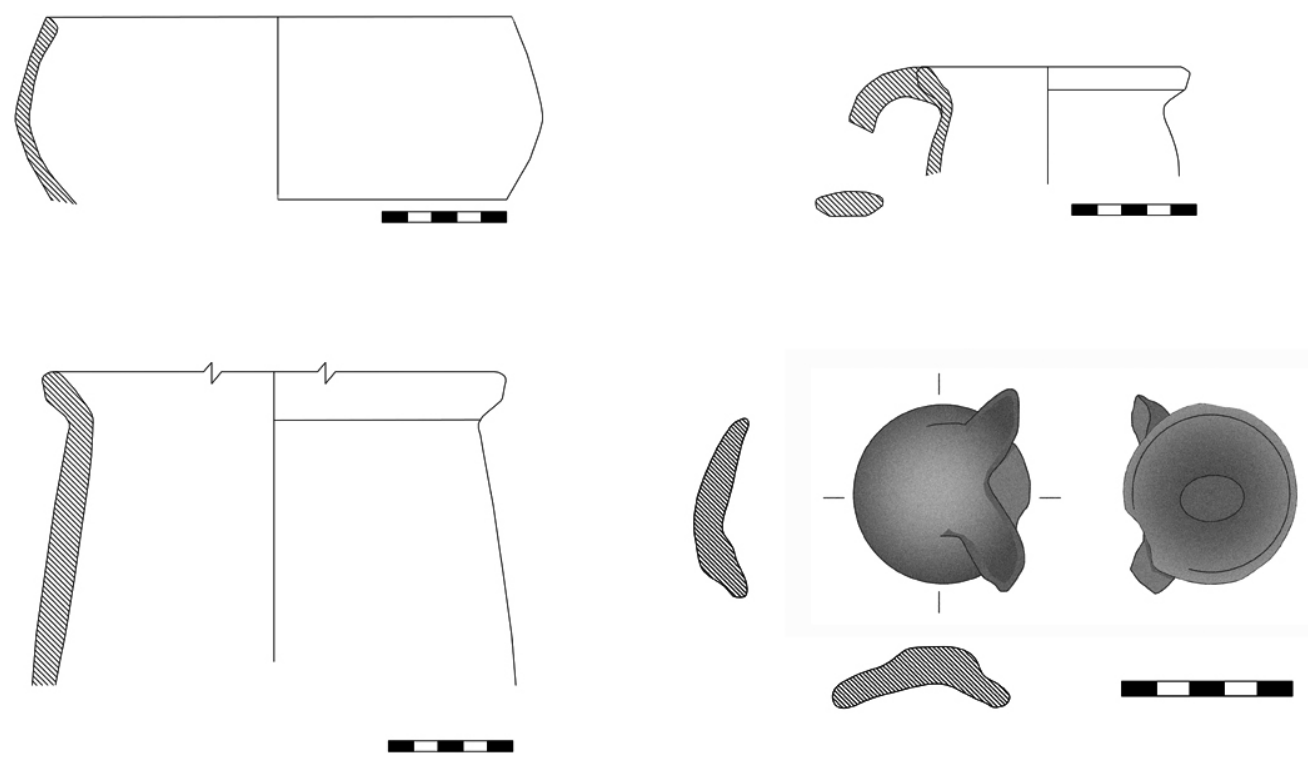

\section{FASE 8}
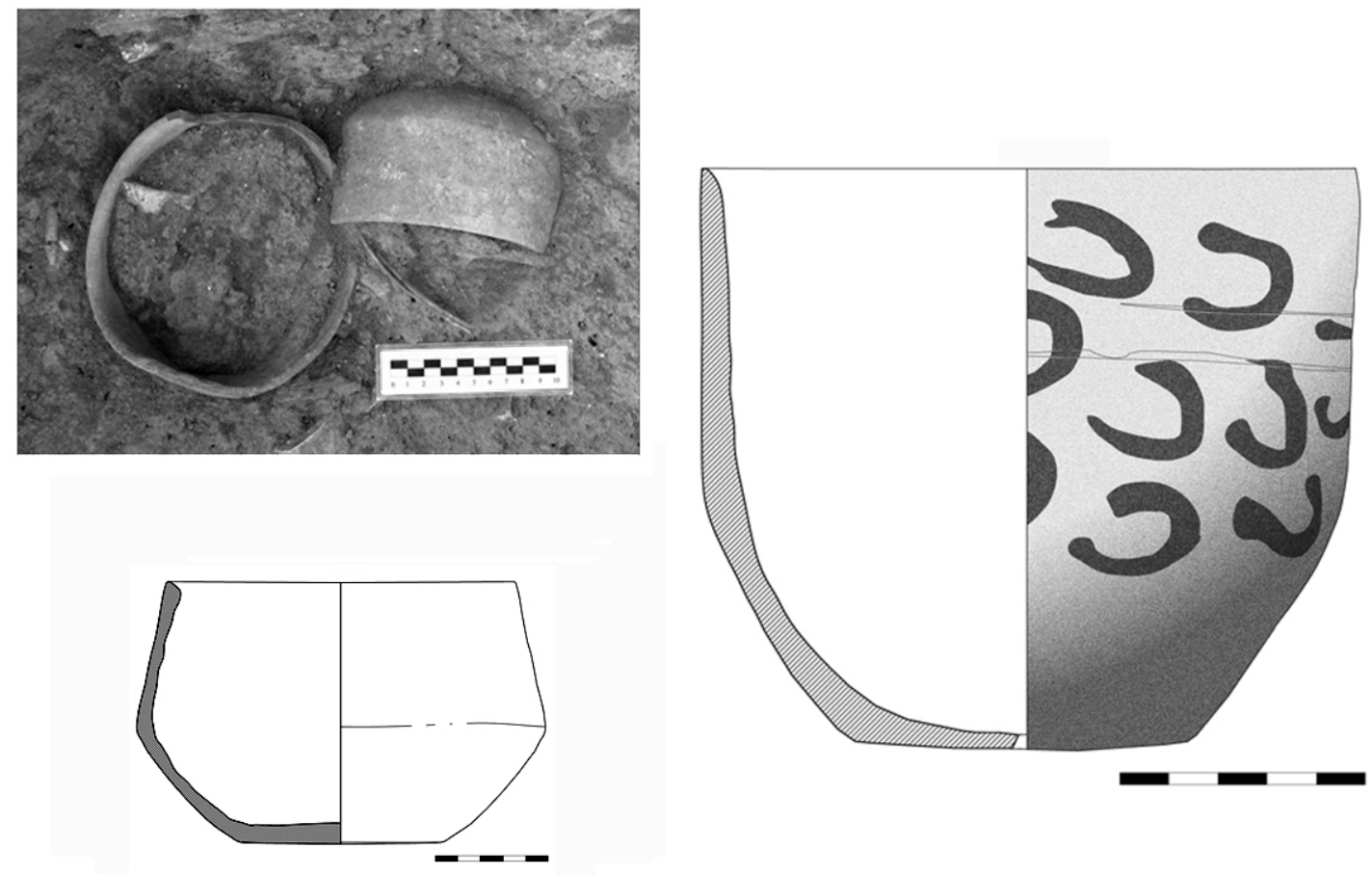

A Figura 8. Material cerámico asociado a las Fases 7 y 8. 


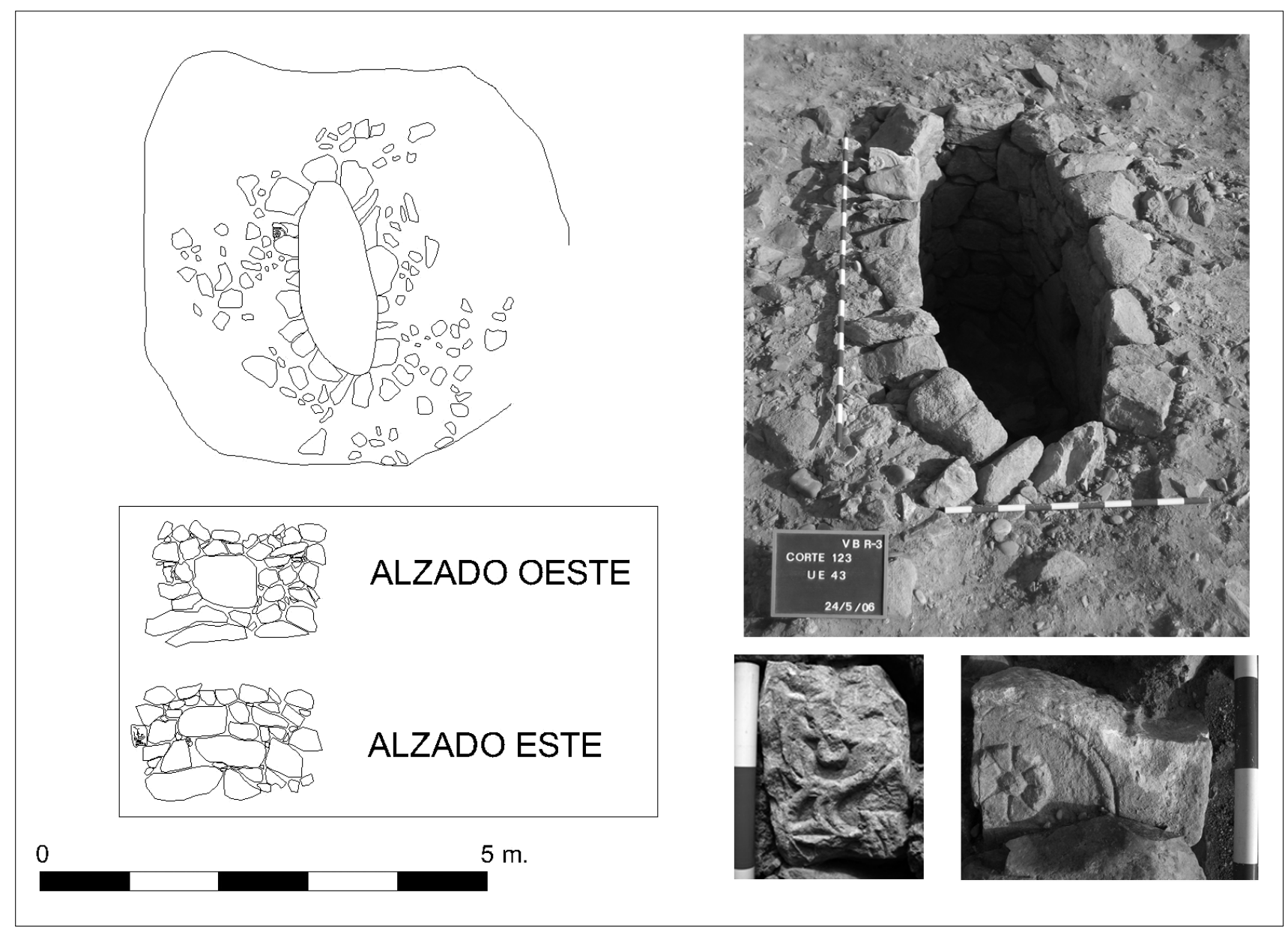

A Figura 9. Fotografía, planta y sección de la noria asociada a la Fase 8. Detalles del material escultórico romano y visigodo reutilizado en su construcción.

previo. Nos referimos a la realización de una gran zanja $(57 \mathrm{x}$ $14 \mathrm{~m}$ ) que discurre de sur a norte en el sector este de R3.

También a esta fase contemporánea hemos de vincular los sondeos de peritación arqueológica realizados en 2001. Se trata de cinco sondeos repartidos por el tercio sur de la parcela.

\section{CONCLUSIONES}

Los trabajos arqueológicos han permitido documentar hasta once fases de ocupación que demuestran el dinamismo histórico de este sector de la ciudad de Toledo. Se ha identificado una ocupación continuada desde el siglo I d. C. hasta el siglo IX d. C., con una frecuentación posterior residual ya que no aparecen estructuras datables con posterioridad a este momento.

La actividad más antigua atestiguada en la R3 arranca en el siglo I d. C. y se corresponde con la extracción de los limos fluviales sedimentarios del río Tajo (Fase 1). La explotación de áridos parece continuarse a lo largo de todo el período romano, como pone de manifiesto la amortización -en un momento indeterminado de la segunda mitad del siglo III/primer cuarto del IV d. C.- de estructuras asociables a la transformación de áridos y de una gran fosa localizada en la mitad sur de la parcela (Fase 2).

Esta actividad extractiva se documenta también en una fase visigoda temprana (Fase 3), previa a la urbanización de la parcela que se produce en un momento indeterminado de la segunda mitad del siglo VI o inicios del VII d. C. (Fases 4 y 5), coincidiendo con la instalación en Toledo de la sede definitiva del poder regio visigodo -Sede Regia- a partir del reinado de Atanagildo. Este hecho histórico implicó la ampliación del tejido urbano de la ciudad más allá del encintado murario de época romana y la urbanización de sectores que hasta el momento se habian mantenido como zonas peri y suburbanas. Las evidencias de esta transformación urbana, se plasman en la parcela R3 con la construcción de un eje viario que discurre de este a oeste y que articula una serie de estructuras domésticas documentadas al norte y sur de la calle. Estas evidencias del urbanismo visigodo en R3 han de ponerse en relación con el estudio de la totalidad del yacimiento de la Vega Baja, máxime teniendo en cuenta que el sector urbanizado documentado en la R3 es muy limitado 
$\left(2800 \mathrm{~m}^{2}\right)$ y se encuentra muy afectado por actividades antrópicas modernas y contemporáneas (Fase 11). A pesar de que esta circunstancia ha condicionado la falta de evidencias asociables a las fases de uso de las estructuras de hábitat visigodas documentadas -apenas parte de la cimentación de las mismas-, es posible atestiguar un abandono del hábitat previo a la utilización de la parcela nuevamente como zona de explotación de áridos en un momento tardovisigodo (Fase 6) y emiral temprano (Fase 7). La última fase histórica documentada en esta parcela corresponde con la conversión de la zona en área de huerta, como evidencia la construcción de una noria en época emiral (Fase 8) amortizada en la Fase 9.

La dificultad, en el estado actual de la investigación, para establecer cronologias a partir de las producciones cerámicas visigodas y emirales tempranas nos impide ajustar la adscripción histórica de estas fases arqueológicas que deberán ser sometidas a una revisión dentro del estudio de conjunto del yacimiento de la Vega Baja y conforme se avance en el conocimiento de los materiales cerámicos de estas décadas.

\section{BIBLIOGRAFÍA}

AA.VV., 2005: Arqueología romana en Toletum, 1985-2004: Puesta en valor de las termas romanas de la Plaza Amador de los Ríos, Los Monográficos del Consorcio 1, Toledo.

ABASCAL, J. M., 1986: La cerámica pintada romana de tradición indígena en la Península Ibérica. Centros de Producción, comercio y tipología, Madrid.

ABASCAL, J. M., 1988: La producción y el comercio de cerámicas como reflejo de la integración de lo indígena y lo romano en la Meseta Sur. Actas 1 Congreso de Historia de Castilla-La Mancha, Tomo IV, Romanos y visigodos: Hegemonía cultural y cambios sociales, Toledo, 125-130.

Aguado Villalba, J., 1983: La cerámica hispanomusulmana de Toledo, Madrid.

Álvarez Delgado, Y., 1989: Cerámicas del siglo IX de Arcávica (Cuenca). Boletín de Arqueología Medieval 3, 109-121.

BAlLEY, D. M., 1980: A catalogue of the Lamps in the British Museum. 2. Roman Lamps in Italy. The Trustees of the British Museum, London.

BALLL, A., 1961-1962: Mosaico con escenas portuarias hallado en Toledo. Homenaje al Prof. Cayetano de Mergelina, Murcia, 123 y ss.

BALLL, A., 1968-1969: Marcas de ceramista en lucernas romanas halladas en España. AEspA 41-42, 158-178.

BalmaSEDA MunCHARAZ, L. J., 2006: En busca de las iglesias toledanas de época visigoda. En Hispania Gothorum. San Ildefonso y el reino visigodo de Toledo, Toledo, 197-214.

Barrio Aldea, C. y Maquedano, B., 1996: Desechos de un taller musulmán en la c/Honda 46. En Toledo; Arqueología en la ciudad, 159-170.

Barrio AldeA, C. y Maquedano, B., 1996b: El corralillo de San Miguel. En Toledo; Arqueología en la ciudad, 207-224.

Barroso, R. y Morín de Pablos, J., 2007: Regia Sedes Toledana. El Toledo Visigodo a través de su escultura monumental, Madrid.

BlÁzouez, J. M., 1982: Mosaicos romanos de la Real Academia de la Historia, Ciudad Real, Toledo, Madrid y Cuenca, CME V, Madrid.

CABALlero ZoREDA, L., 1989: Cerámicas de época visigoda y postvisigoda de las provincias de Cáceres, Madrid y Segovia. Boletín de Arqueología medieval 3, 75-108.

Caballero Zoreda, L. y Juan Tovar, L. C., 1983-84: Terra Sigillata Hispánica Brillante. Empúries 45-46, 154-193.

Caballero Zoreda, L. y Mateos Cruz, P. (eds.), 2000: Visigodos y Omeyas. Un debate entre la Antigüedad Tardía y la Alta Edad Media. Anejos de AEspA XXIII, Madrid.

Caballero Zoreda, L., Retuerce Velasco, M. y Sáez Lara, F., 2003: Las cerámicas del primer momento de Santa María de Melque (Toledo), construcción, uso y destrucción. En CABallero, L., Mateos, P. y ReTUERCE, M. (eds.), 2003: Cerámicas tardorromanas y altomedievales en la Península lbérica. Ruptura y Continuidad, Anejos de AEspA XXVIII, Madrid, 225-271.

Caballero, L., Mateos, P. y Retuerce, M. (eds.), 2003: Cerámicas tardorromanas y altomedievales en la Península lbérica. Ruptura y Continuidad. Anejos de AEspA XXVIII, Madrid.
Carrobles Santos, J., 1987: Aportación al estudio de las cerámicas tipo "Meseta Sur". Carpetania: Revista del Museo de Santa Cruz 1, Toledo, 265-269.

CARRobles SANTOS, J., 1990: Introducción a la arqueología urbana de la ciudad de Toledo. En Actas del I Congreso de Arqueología de la Provincia de Toledo, Toledo, 487-490.

Carrobles Santos, J., 1999: La ciudad de Toledo en la Antigüedad Tardía. En García Moreno, L. y Rascón Marqués, S. (eds.): Complutum y las ciudades hispanas en la Antigüedad Tardía. Acta Antiqva Complvtensia I, Alcalá de Henares (1996), 193-2000.

Carrobles Santos, J., 2001: El teatro romano de Toledo. Una propuesta de identificación. Toledo.

Carrobles Santos, J. y Rodriguez, S., 1988: Memoria de las excavaciones de urgencia del solar del nuevo mercado de Abastos (Polígono Industrial, Toledo). Introducción al estudio de la ciudad de Toledo en el siglo IV d.C. Madrid.

Carrobles Santos, J., Barroso Cabrera, R., Morin de Pablos, J. y Valdés FerNÁNDEZ, F., 2007: Regia Sedes Toledana. La topografía de la ciudad de Toledo en la Antigüedad tardía y la Alta Edad Media. Madrid.

Delgado Valero, C., 1986: El cementerio musulmán de Toledo, Toledo Hispanoárabe, Toledo. (Publicado en Delgado Valero, 2001, 83-89).

Delgado Valero, C., 1987: Toledo islámico: ciudad, arte e historia. Toledo.

Delgado Valero, C., 1987b: Formas islámicas toledanas, Tesis Doctoral Dpto. de Historia del Arte Medieval, Árabe y Cristiano, Universidad Complutense de Madrid (3 tomos). Madrid.

Delgado Valero, C., 1987c: Materiales para el estudio morfológico y ornamental del arte islámico en Toledo. Museo de Santa Cruz, Estudios y Monografias 3. Toledo.

Delgado VAlero, C., 1990: Arqueologia islámica de la ciudad de Toledo, Actas del I Congreso de Arqueología de la provincia de Toledo. Toledo.

Delgado Valero, C., 1991: Estructura urbana de Toledo en época islámica. En La ciudad islámica. Zaragoza, 321-341.

Delgado Valero, C., 2001: Arte Hispano-Musulmán (artículos), Homenaje a Clara Delgado Valero. Madrid.

Delgado Valero, C., 1999: La estructura urbana de Toledo en época islámica. En Delgado Valero, C., Meouak, M., Aguado, J. et alii, 1999: Regreso a Tulaytula. Guía del Toledo islámico (siglos VIII-XI). Toledo, 15-157.

Delgado Valero, C., Meouak, M., Aguado, J. et alii, 1999: Regreso a Tulaytula. Guía del Toledo islámico (siglos VIII-XI). Toledo.

Fernández Del CerRo, J., 2005: Un conjunto de materiales de época altoimperial en Calle Real 4, 6 y 8, en Arqueología romana en Toletum, 1985-2004: Puesta en valor de las termas romanas de la Plaza Amador de los Ríos. Los Monográficos del Consorcio 1. Toledo, 77-80.

Fernández Garcia, Ma I. y Roca Roumens, M., 2008: Producciones de Terra Sigillata Hispánica. En Bernal, D. y Ribera, A. (eds.): Cerámicas hispanorromanas. Un estado de la cuestión. Cádiz, 307-332.

Fernández OChOA, C. y Zarzalejos, M., 2008: Terra Sigillata Hispánica BriIlante (TSHB). En Bernal D. y Ribera, A. (eds.): Cerámicas hispanorromanas. Un estado de la cuestión, Cádiz, 333-342. 
Fernández Ochoa, C., Zarzalejos, M., Garcia Entero, V., Garcia Marcos, V., Menéndez Granda, A., Sánchez Hidalgo, E. y Foucher, V., 2005: La difusión de los talleres de La Graufesenque y Montans en el cuadrante noroccidental de Hispania: Materiales para un corpus de marcas de alfarero. En La difusió de la Terra Sigillata sudgàlllica al nord d'Hispania, Monografies n. ${ }^{\circ}$ 6, Barcelona, 79-102,

Garcia Sánchez, J., 1996: Paseo de la Basilica, 92. Toledo.

GaRcia SÁnChEZ, J., 2005: Nuevas aportaciones de restos romanos, en AA.W., 2005: Arqueología romana en Toletum, 1985-2004: Puesta en valor de las termas romanas de la Plaza Amador de los Ríos. Los Monográficos del Consorcio 1. Toledo, 201-205.

Garcia SÁnchez, J. y Gómez Garcia, F. M., 2005: Nuevas piezas para el estudio de la cerámica romana del tipo "Meseta Sur" de Toledo. En AA.W., 2005: Arqueología romana en Toletum, 1985-2004: Puesta en valor de las termas romanas de la Plaza Amador de los Ríos. Los Monográficos del Consorcio 1. Toledo, 215-219.

Garcia Sánchez, J. y Gómez Garcia, F. M., 2005b: Nuevas inscripciones funerarias de Toletum. En AA.W., 2005: Arqueología romana en Toletum, 1985-2004: Puesta en valor de las termas romanas de la Plaza Amador de los Ríos. Los Monográficos del Consorcio 1. Toledo, 207-212.

IzQuierdo Benito, R., 2006: La urbs regia, en Hispania Gothorum. San IIdefonso y el reino visigodo de Toledo. Toledo, 143-159.

JUAN GARCiA, A., 1987: Los enterramientos musulmanes del circo romano de Toledo. Museo de Sta. Cruz, Estudios y Monografías 2, Toledo.

Juan Tovar, L. C., 2000: La terra sigillata de Quintanilla de la Cueza, en Garcia Guinea, M. A. (dir.): La villa romana de Quintanilla de la Cueza (Palencia). Memoria de las excavaciones 1970-1981. Salamanca, 45-122.

Maquedano Carrasco, B., Rojas, J. M.; Sánchez Peláez, E. I., Sáinz Pascual, Ma J. y VILLA GonzÁLEZ, J. M., 2002a: Nuevas aportaciones al conocimiento de las necrópolis medievales de la Vega Baja de Toledo (I). Tulaytuya 9, 19-53.

Maquedano Carrasco, B., Rojas, J. M.; Sánchez Peláez, E. I., Sáinz Pascual, $M^{a}$ J. y VILLA GonZÁLEZ, J. M., 2002b: Nuevas aportaciones al conocimiento de las necrópolis medievales de la Vega Baja de Toledo (y II). Tulaytuya 10, 27-68.

Maquedano Carrasco, B., y Sánchez Peláez, E. I., 2005: El toletum de papel. En Arqueología romana en Toletum: 1985-2004. Puesta en valor de las termas romanas de la Plaza Amador de los Ríos. Los Monográficos del Consorcio 1. Toledo, 159-170.

MÉLIDA, J. R., 1923: Un mosaico descubierto en Toledo. BRAH 83, 19 y ss.

PALOL, P. de, 1991: Resultado de las excavaciones junto al Cristo de la Vega, supuesta basilica conciliar de Santa Leocadia, de Toledo. Algunas notas de topografia religiosa de la ciudad. En XIV Centenario del Concilio de Toledo. Toledo, 787-832.

Pérez González, C. y Juan Tovar, L. C., 1988: Notas para el estudio de la Terra Sigillata Galica en la Provincia de Toledo. En Actas 1 Con- greso de Historia de Castilla-La Mancha, Tomo IV Romanos y visigodos: Hegemonia cultural y cambios sociales. Toledo, 145-150.

PerIS, D., 1999: La Fábrica de Armas de Toledo. I. Historia. Toledo.

PERIS, D. et alii, 2003: Dos siglos en construcción: de Fábrica de armas a campus universitario. Madrid.

RIPoLL, G., 2000: Sedes Regiae en la Hispania de la Antigüedad Tardía, en Sedes regiae (ann. 400-800). Barcelona, 371-401.

RIPOLL, G. y GURT. J. Ma, 2000: Sedes regiae (ann. 400-800), Reial Acadèmia de Bones Lletres. Barcelona.

Rodriguez Martin, F. G. y Alonso CerezA, E., 2005: Lucernas. Vidrios: Antigüedades Romanas II, Real Academia de la Historia. Catálogo del Gabinete de Antigüedades. Madrid.

Rojas Rodriguez-Malo, J. M., 1996: Paseo de la Rosa, 76 (la piscina romana de Cabrahigos). En Toledo: Arqueología en la ciudad. Toledo, 67-81.

Rojas Rodriguez-Malo, J. M. y Gómez LAguna, A. J., 2006 e.p.: La cerámica visigoda de La Vega Baja de Toledo. En VIII Congreso Internacional de Cerámica Medieval en el Mediterráneo, (Ciudad Real-Almagro, 27 de feb.-3 de marzo de 2006).

Rojas Rodriguez-Malo, J. M. y Gómez Laguna, A. J., 2009: Intervención arqueológica en la Vega Baja de Toledo. Caracteristicas del centro político y religioso del reino visigodo, en Caballero, L., Mateos, P. y Utrero, M. ${ }^{a}$ A. (eds.): El siglo VI frente al siglo VII: Arquitectura, Arrejos de AEspaA LI, Madrid, 45-90.

Rojas Rodríguez-Malo, J. M. y Villa González, R., 1996: Consejería de obras públicas. En Toledo. Arqueología de la Ciudad. Patrimonio Histórico arqueológico de Castilla-La Mancha 13. Toledo, 225-237.

San Román, F. de B., 1934: El segundo mosaico de la Vega Baja de Toledo. Anuario del Cuerpo Facultativo de Archiveros, Bibliotecarios y Arqueólogos, 1934, II, 339 y ss.

Sánchez Palencia, F. J. y Sáinz Pascual, M. J., 1988: El circo romano de Toledo: Estratigrafía y arquitectura, Toledo.

Sánchez Palencia, F. J., Sáinz Pascual, M. J. y Juan Garcia, A., 1988: Estratigrafía y arquitectura del circo romano de Toledo. En Actas 1 Congreso de Historia de Castilla-La Mancha, Tomo IV Romanos y visigodos: Hegemonía cultural y cambios sociales. Toledo, 225-236.

Sánchez Palencia, F. J. y Sáinz Pascual, M. J., 2001: El Circo de Toletum. En El Circo en Hispania Romana. Mérida, 97-115.

TsIoLIS, V., 2005: Materiales cerámicos y contexto estratigráfico en la Puerta del Sol. En AA.W., 2005: Arqueología romana en Toletum, 1985-2004: Puesta en valor de las termas romanas de la Plaza Amador de los Ríos. Los Monográficos del Consorcio 1, 83-85.

VELASCO, I. y RIPOLL, G., 2000: Toletvm, la construcción de una Vrbs Regia, en Sedes Regiae (ann. 400-800). Barcelona, 521-578.

Zarzalejos Prieto, M., 1991: El yacimiento romano de Velilla de San Antonio (Madrid). La Terra Sigillata. Madrid.

Zarzalejos Prieto, M., 2002: El alfar romano de Villamanta (Madrid). Madrid. 